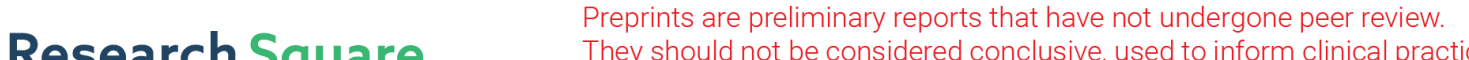 They should not be considered conclusive, used to inform clinical practice, or referenced by the media as validated information. \\ Landslide Susceptibility Zonation Using Statistical and Machine Learning Approaches in Northern Lecco, Italy
}

Mohammad Mehrabi ( $\nabla$ mohammad.mehrabi@mail.polimi.it )

Polytechnic of Milan - Lecco Campus: Politecnico di Milano - Polo territoriale di Lecco

\section{Research Article}

Keywords: Geo-hazard landslide, Susceptibility assessment, Frequency ratio, Artificial neural network, Neuro-fuzzy model

Posted Date: August 6th, 2021

DOI: https://doi.org/10.21203/rs.3.rs-771789/v1

License: (c) (i) This work is licensed under a Creative Commons Attribution 4.0 International License. Read Full License

Version of Record: A version of this preprint was published at Natural Hazards on November 10th, 2021. See the published version at https://doi.org/10.1007/s11069-021-05083-z. 


\title{
Landslide Susceptibility Zonation Using Statistical and Machine Learning Approaches in Northern Lecco, Italy
}

\author{
Mohammad Mehrabi \\ Department of Civil and Environmental Engineering, Politecnico di Milano, Milan, Italy \\ Email: mohammad.mehrabi@mail.polimi.it
}

\section{Abstract}

This study deals with landslide susceptibility mapping in the northern part of Lecco Province, Lombardy Region, Italy. In so doing, a valid landslide inventory map and thirteen conditioning factors (including elevation, slope aspect, slope degree, plan curvature, profile curvature, distance to waterway, distance to road, distance to fault, soil type, land use, lithology, stream power index, and topographic wetness index) form the spatial database within geographic information system (GIS). The used evaluative models comprise a bivariate statistical approach called frequency ratio (FR) and two machine learning tools, namely multi-layer perceptron neural network (MLPNN) and adaptive neuro-fuzzy inference system (ANFIS). These models first use landslide and non-landslide records for comprehending the relationship between the landslide occurrence and conditioning factors. Then landslide susceptibility values are predicted for the whole area. The accuracy of the produced susceptibility maps is measured using area under the curve (AUC) index, according to which, the MLPNN $($ AUC $=0.916)$ presented the most accurate map, followed by the FR $(A U C=0.898)$ and ANFIS (AUC $=0.889$ ). Visual interpretation of the susceptibility maps, FR-based correlation analysis, as well as the importance assessment of conditioning factors, all indicated the significant contribution of the road networks to the crucial susceptibility of landslide. Lastly, an explicit predictive formula is extracted from the implemented MLPNN model for a convenient approximation of landslide susceptibility value.

Keywords: Geo-hazard landslide; Susceptibility assessment; Frequency ratio; Artificial neural network; Neuro-fuzzy model. 


\section{Introduction}

31 Landslide is a ubiquitous environmental disaster that is responsible for nearly $17 \%$ of life losses and exclusively accounts for about 5\% of the natural catastrophes worldwide (Kjekstad and Highland 2009, Pham et al. 2019). Different definitions and classification systems have been proposed for landslides (Li and Mo 2019). Cruden (1991), for instance, explained landslide as mass movements of rock, earth or debris down a slope. It may not be feasible to stop or control the landslide. Nevertheless, utilizing decision support systems for recognizing landslide-prone areas is an effective way toward mitigating the corresponding damages (Thai Pham et al. 2019).

Landslide is a dynamic phenomenon (Pandey et al. 2021) whose susceptibility assessment requires taking the effect of several parameters into consideration (Hua et al. 2021). Due to this reason, scholars have tested various strategies such as statistical analysis (Reichenbach et al. 2018), decision making (Yoshimatsu and Abe 2006), and soft computing (Huang and Zhao 2018) for susceptibility (and hazard) assessment of landslide (Catani et al. 2005). Yalcin (2008) used three models including analytical hierarchy process (AHP), statistical index (SI), and weighting factor for landslide susceptibility mapping at Ardesen region, Turkey. Regmi et al. (2014) examined the efficiency of the FR, SI, and weights-of-evidence for mapping the susceptibility of landslide in central regions of Nepal Himalaya. It was shown that the FR with success rate and predictive accuracy of $76.8 \%$ and of $75.4 \%$, respectively, performed better than two other models. The applicability of decision-making models has been investigated in various studies (Mirdda et al. 2020, Maqsoom et al. 2021, Pham et al. 2021). Pourghasemi et al. (2012) produced the landslide susceptibility map of the Safarood Basin, located in the Northern part of Iran, using index of entropy and conditional probability techniques. Both models presented higher than $82 \%$ accuracy which indicates the reliability of the maps. 
52 Machine learning models have greatly assisted engineers in coping with many non-linear problems,

53 including the evaluation of environmental phenomena like forest fire (Bui et al. 2019), flood (스-

54 Abadi 2018), groundwater potential (Naghibi et al. 2016), gully erosion (Gayen et al. 2019), etc.

55 Recent decades have witnessed the increasing popularity of various machine learning models.

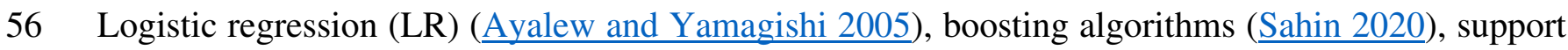

57 vector machine (Pourghasemi et al. 2013), tree-based approaches (ong et al. 2018), and neighbor-

58 based methods (El-Magd et al. 2021) are some of the well-known machine learning models that have

59 been effectively used for landslide-related analysis, particularly susceptibility assessments.

Artificial neural network (ANN) and adaptive neuro-fuzzy inference system (ANFIS) are other notions of soft computing that have powerfully served for exploring non-linear engineering parameters. These models use sophisticated algorithms to dig and learn the pattern of the intended parameters. Pradhan et al. (2010) and Lee et al. (2003) tested and professed the feasibility of ANNs for landslide susceptibility mapping. Similar evaluations have been reported by $\underline{\mathrm{Oh} \text { and Pradhan }}$ $\underline{\text { (2011) }}$ and Vahidnia et al. (2010) for the ANFIS. Jacinth Jennifer and Saravanan (2021) manifested a successful application of ANNs for susceptibility estimation of landslide in Idukki district of India. It was observed that the ANN models with a more complex structure achieved above $90 \%$ accuracy of prediction. Mehrabi et al. (2020) trained an ANFIS model using metaheuristic approaches. They showed that genetic algorithm (GA) is a suitable algorithm for optimizing the parameters of membership functions in ANFIS. In research by Hong et al. (2020), the GA showed nice performance also for supervising multi-layer perceptron neural network (MLPNN). Further applications of the MLPNN model for predicting environmental threats can be found in (Yi et al. 2020, Avand and Moradi 2021, Mohajane et al. 2021).

74 Comparative studies have always released valuable findings toward a convenient selection of landslide evaluative models (Nhu et al. 2020, Nhu et al. 2020, Panahi et al. 2020). In many works, 
scholars have declared the better efficiency of soft computing models compared to traditional statistical tools. Park et al. (2013) compared the performance of ANN with several FR, AHP, and LR for landslide susceptibility mapping in Inje region, Korea. According to the respective values of area under the curve (AUC) $0.789,0.794,0.794$, and 0.806 obtained for the AHP, FR, LR, and ANN, the superior accuracy of the ANN was deduced. A similar effort and conclusion were reported by Yilmaz (2009) for a case study from Kat landslides in Tokat City of Turkey. Sadighi et al. (2020) showed the ANFIS model outperforms ANN for landslide susceptibility modeling at Tajan Watershed, Northern Iran. The AUC values were 0.902 and 0.866. However, a hybrid ANFIS (coupled with imperialist competitive algorithm) with an AUC equal to 0.966 was found to be superior over both regular ANFIS and ANN. Lucchese et al. (2021) employed and compared the ANN with ANFIS for the same purpose in Rolante river basin, Brazil. Based on the calculated AUCs, 0.8886 for ANFIS and 0.9409 for ANN, the later model could achieve a considerably larger accuracy.

The present research aims to produce applicable landslide susceptibility maps for the northern part of Lecco Province, Italy. This country, owing to its relief and lithological and structural features, is characterized by particularly high landslide risk (Trigila and Iadanza 2008). Having a look at the existing literature, while some studies have dealt with landslide susceptibility prediction in different parts of the Lombardy Region (Sterlacchini et al. 2011, Fabbri and Patera 2021), Lecco demands to receive proper analysis for alleviating the risk of this catastrophe in this prone area.

Three different methodologies consisting of one traditional statistical method, namely frequency ratio, and two artificial intelligence models, namely MLPNN and ANFIS, are employed in this research to predict landslide susceptibility value (LSV) all over the area. The above studies have professed the high efficiency of these three models (i.e., FR, ANN, and ANFIS) in the field of landslide susceptibility assessment. In the following, the case study and used database are introduced and spatial interactions are investigated. Then, the models are executed to produce and interpret the 
100 susceptibility maps. It is followed by accuracy assessment along with comparative validation of the

101 results, and finally, the study ends up with introducing a neural-based LSV predictive formula.

\section{Data and case study}

\section{$104 \quad 2.1 \quad$ Study area}

105 The case of this research is the Northern part of the Lecco province located in the Lombardy region, 106 Italy. Figure 1 shows the exact location of the study area. It lies within the longitude $09^{\circ} 15^{\prime}$ to $09^{\circ}$ $10732^{\prime} \mathrm{E}$ and latitude $45^{\circ} 50^{\prime}$ to $46^{\circ} 09^{\prime} \mathrm{N}$ adjacent to the Como Lake. The area is roughly $473 \mathrm{~km}^{2}$ and 108 referring to the 2007 census, the province of Lecco has nearly 340000 inhabitants (Parente et al. 109 2013). This region is under a warm and temperate climate with an annual rainfall around $1360 \mathrm{~mm}$. 110 According to online meteorological data (www.en.climate-data.org, www.worldweatheronline.com), 111 the average monthly temperature ranges from $0{ }^{\circ} \mathrm{C}$ in January to $19.1{ }^{\circ} \mathrm{C}$ in August. The altitude 112 varies from $197.3 \mathrm{~m}$ to $2608.6 \mathrm{~m}$. The range of slope starts from 0 and peaks at around $87^{\circ}$ close to 113 the summits. According to the soil map, Cambisol is the dominant soil type covering around $45 \%$ of 114 the area. Geologically, the area includes 43 units, out of which, the largest coverage is reported for 115 Limestones and Dolomite. Considering the utilization of land, most of the area is classified as forest 116 and semi-natural. 


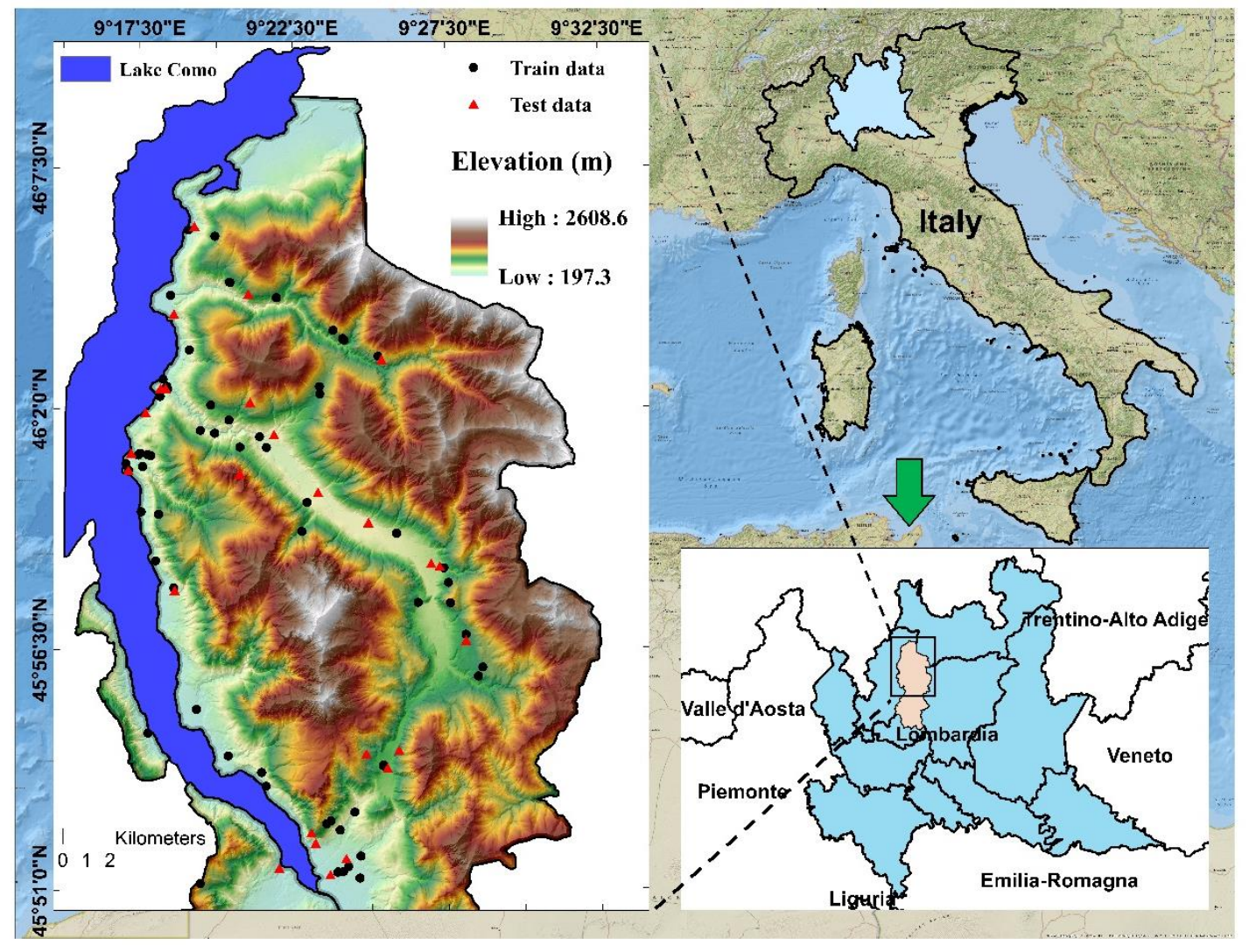

Figure 1: The study area and distribution of the landslides.

\subsection{Landslide inventory map}

121 Inventory maps are essential prerequisites for spatial analysis of environmental threats like landslides

122 (Varnes 1984, Can et al. 2019). They illustrate the distribution of the past events within the area of

123 interest, and contain also information regarding the date, outlines, and characteristics of occurrence

124 (Singh and Kumar 2018, Chen et al. 2020). The inventory map used in this study merges the

125 information of two published inventory maps. As Figure 1 shows, a total of 92 landslides are

126 identified in the geographic information system (GIS). Out of these events, 82 landslides (18 areal +

12764 single) are taken from the inventory map prepared by Calvello and Pecoraro (2018), and 10 
128 landslides are taken from the database provided by the Inventario dei Fenomeni Franosi in Italia 129 (IFFI).

130 The landslides taken from the first dataset occurred between early-2010 and late-2019, while the 131 events taken from the IFFI dataset took place between 2000 and 2011. Considering the severity, the

132 landslides are mostly classified as C2: severe events with injured persons and/or evacuations, and C3:

133 minor events which did not cause any physical harm to people (Calvello and Pecoraro 2018).

134 To create the spatial database of this study, a total of 92 non-landslide points are randomly generated 135 within the areas without landslides. Based on a random selection, 70\% of the landslides (i.e., 64 136 points) and $70 \%$ of the non-landslides (i.e., 64 points) are selected as training data, while the 137 remaining 30\% (i.e., 28 landslides and 28 non-landslides) constitute the testing dataset.

\subsection{Conditioning factors and correlation assessment}

140 The susceptibility of landslide is a function of several parameters that can affect the occurrence of

141 this phenomenon. Therefore, proper selection of these parameters is of great importance (Dou et al. 142 2020, $\mathrm{Li}$ et al. 2021). Moreover, reliability of data is another key parameter as it contributes to the 143 quality of data (Mandal et al. 2021). In the present study, thirteen landslide conditioning factors, 144 namely elevation, slope aspect, slope degree, plan curvature, profile curvature, distance to waterway, 145 distance to road, distance to fault, soil type, land use, lithology, stream power index (SPI), and 146 topographic wetness index (TWI) are taken into the equation to predict the LSV. For preparing these 147 layers, the essential required layers were digital elevation model (DEM), the shapefile of linear 148 phenomena (i.e., waterways, roads, and faults), as well as the shapefiles of soil type, land use, and 149 geology map. All mentioned layers were downloaded from the website of Territorial Information of 150 Region Lombardy (Geoportal of the Lombardy Region: 


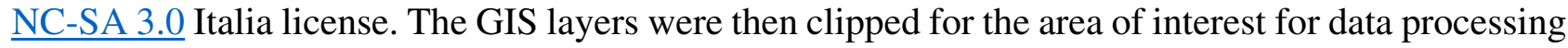
and subsequent analysis. According to the source metadata, the DEM layer has been provided with $5 \times 5 m$ spatial resolution using various resources such as local topographical data, $1 \times 1 m$ resolution Lidar surveys, and the former edition of the $20 \times 20 m$ regional DEM (metadata).

Apart from the elevation layer that is represented by the DEM, the layers of slope aspect, slope degree, plan curvature, and profile curvature were directly produced from DEM. Figure 2 - (a) shows the elevation map. The altitude values range from $197.3 m$ to $2608.6 m$ which were classified into six groups including < 200, $(200-700),(700-1200),(1200-1700),(1700-2200)$, and $>2200 \mathrm{~m}$. The slope aspect, which illustrates the direction of slope face, has local influences on inducing instabilities 161 of slopes (Chawla et al. 2019). Figure 2 - (b) shows the slope aspect. Based on the GIS classification, this layer has the following groups: Flat, North, North-East, East, South-East, South, South-West, West, and North-West. Famously, the slope is one of the most relevant factors in landslide susceptibility assessment which demonstrates the rate of change in altitude (Mathew et al. 2009, Mokarram and Zarei 2018). The produced slope map is presented in Figure 2 - (c). Based on this map, the gentlest and steepest terrains are represented by the slopes of $0^{\circ}$ and $86.7^{\circ}$, respectively. This layer was classified into $<15,(15-25),(25-35),(35-45)$, and $>45^{\circ}$ (Tangestani 2009). Plan curvature is an indicator of flow acceleration and erosion/deposition rate and profile curvature can impact the variation of flow velocity down the slope (Kalantar et al. 2018, Moayedi et al. 2019). Figures $2-(d)$ and (e) show the map of these two layers. The sub-classes of plan curvature were (1897.01 - -59.10), (-59.10 - -22.34), (-22.34 - -10.09), (-10.09-51.16), and (51.16 - 1239.68), while the profile curvature consists of (-952.57 - -35.78), (-35.78 - -13.05), (-13.05 - -5.47), (-5.47 - 39.98), and (39.98 - 987.08) sub-classes. 
174 Distance to linear features (i.e., waterways, road, and fault) has been among the most crucial 175 conditioning factors for landslide susceptibility modeling that have been regarded in many previous 176 efforts (Ozdemir and Altural 2013, Pradhan and Siddique 2020, Razavi-Termeh et al. 2021, Saha et 177 al. 2021). Figures 2 - (f), (g), and (h) depict the maps of distance to waterways, distance to road, and 178 distance to fault, respectively. The distribution of previous events indicates that the majority of 179 landslides have occurred along with the named linear phenomena. The distance classes of $(0-50)$, 180 (50 - 100), (100 - 150), and >150 $m$ were applied for the waterways and roads, while the map of 181 distance to fault was grouped into $(0-200),(200-400),(400-700),(700-1000)$, and $>1000 \mathrm{~m}$ 182 (Tangestani 2009).

183 Soil type is another important parameter that contributes to the occurrence of landslides through 184 characteristics like permeability and cohesiveness (Avtar et al. 2011, Mandal et al. 2018). Seven soil 185 categories are detected in the soil type map which is presented in Figure 2 - (i). These categories are 186 originally Cambisols, Regosols, Fluvisols, Umbrisols, Cambisols podzolici, Leptosols, Luvisols that 187 are represented by A, B, .., G in the corresponding map, respectively. The land use map was cropped 188 from the CORINE Land Cover (CLC) layer. In the CLC legend, the utilizations are categorized into 189 five major classes: (a) artificial surfaces, (b) agricultural areas, (c) forest and semi-natural areas, (d) 190 water lands, and (e) water bodies. Each major class is further divided into two levels of classification. 191 Consequently, a three-digit number indicates the land use of each sub-class (e.g., 312 stands for the 192 land use category that is the $2^{\text {nd }}$ sub-class belonging to the $1^{\text {st }}$ class of the $3^{\text {rd }}$ major category). More 193 details regarding this layer can be found in (www.geoportale.regione.lombardia.it/en , 194 www.land.copernicus.eu). Figure 2 - (j) displays the land use layer for the intended area. This map 195 comprises 19 classes which are detailed in Table 1. 


\begin{tabular}{llllll}
\hline $\begin{array}{l}\text { CLC } \\
\text { code }\end{array}$ & Name & Description & $\begin{array}{l}\text { CLC } \\
\text { code }\end{array}$ & Name & Description \\
\hline 312 & A & Coniferous forests & 324 & $\mathrm{~K}$ & $\begin{array}{l}\text { Transitional woodland/shrub } \\
\text { Road and rail networks and }\end{array}$ \\
231 & B & Pastures & 122 & $\mathrm{~L}$ & associated land \\
243 & C & Principally agricultural with & & & \\
313 & D & Mignificant natural vegetation & 121 & $\mathrm{M}$ & Industrial or commercial units \\
311 & E & Broad-leaved forest & 332 & $\mathrm{~N}$ & Bare rock \\
321 & F & Natural grassland & 512 & $\mathrm{O}$ & Water bodies \\
211 & G & Non-irrigated arable land & 242 & $\mathrm{P}$ & Complex cultivation patterns \\
511 & H & Water courses & 131 & $\mathrm{Q}$ & Mineral extraction sites \\
112 & I & Discontinuous urban fabric & 333 & $\mathrm{R}$ & Sparsely vegetated areas \\
322 & J & Moors and heathland & 111 & $\mathrm{~S}$ & Continuous urban fabric \\
\hline
\end{tabular}

199 Lithology is a crucial parameter in landslide-related assessments as it can affect the formation and 200 evolution of landslides, as well as the type and scale of this phenomenon (Yalcin et al. 2011, $\underline{\text { Pham }}$ 201 et al. 2018, Xiao et al. 2019). Based on the lithology map (scale: 1:250000) shown in Figure $2-(\mathrm{k})$, 202 a total of 43 geological units can be found in this area. As explained in Table 2, these layers are named $203 \mathrm{~A}, \mathrm{~B}, \ldots, \mathrm{Z}, \mathrm{AA}, \mathrm{AB}, \ldots \mathrm{AQ}$.

Table 2: Description of the geological units.

\begin{tabular}{lll}
\hline Label & Original Description (In Italian) & Lithology \\
\hline A & "Ortogneiss" e "Gneiss chiari" Auct. & Granitic and granodioritic Gneisses, Porphyroid \\
B & "Andesiti" ("Porfiriti" Auct.) & Andesites with Dacites, basalts, and Rhyolites \\
C & "Dolomia Principale" & Dolomites \\
D & anfiboliti (intercal.nei basam.cristallini) & Amphibolites \\
E & "Selcifero lombardo" & Flints Marl Limestone \\
F & Gneiss di Morbegno e altri & Paragneiss \\
G & marmi (intercal.nei basam.cristallini) & Marbles (crystalline Limestones) \\
H & morenico tardo-wurmiano e local. olocenico & Gravels, Blocks, Silts \\
I & "Verrucano lombardo" & Conglomerates, Sandstones \\
J & Cgl. del Ponteranica e del Dosso dei Galli & Conglomerates \\
K & conoidi & Conoids \\
\hline
\end{tabular}




\begin{tabular}{|c|c|c|}
\hline $\mathrm{L}$ & Fmz. di Collio & Sandstones, Siltstones, Argillites \\
\hline M & "Servino" & Sandstone, Marl, Siltstone, Argillite, Limestone; Siderite \\
\hline $\mathrm{N}$ & "Micascisti dei Laghi" & Prevalent Mica Schists \\
\hline $\mathrm{O}$ & "Dolomia a Conchodon" & Limestone and Dolomitic Limestone \\
\hline $\mathrm{P}$ & Detriti di falda e frane & Groundwater debris and landslides \\
\hline Q & Fmz. di Wengen/Fmz. di Buchenstein & Marl, Aren., calc., argil./calc. Sel., Aren., Marl, dol. S \\
\hline $\mathrm{R}$ & "Rosso Ammonitico lombardo"/"Medolo" & Marls, Marly Limestones/Lombard Flint Limestones \\
\hline S & Calcare di Prezzo/Calcare di Angolo & Limestones \\
\hline $\mathrm{T}$ & Calcare di Esino e "Calcare rosso" & Limestones \\
\hline $\mathrm{U}$ & Fmz. di San Giovanni Bianco & Argillites, Marls, Limestones, carnioles \\
\hline $\mathrm{V}$ & Fmz. di Gorno & Limestone, Marl, sandstone, Argillite \\
\hline $\mathrm{W}$ & Argillite di Riva di Solto & Shales \\
\hline $\mathrm{X}$ & morenico Wurm & Gravels, Bubbles and Silts \\
\hline Y & Calcare di $\mathrm{Zu}$ & Limestones \\
\hline $\mathrm{Z}$ & Carniola di Bovegno & Carneole \\
\hline AA & rioliti ("Porfidi quarziferi" Auct.) & $\begin{array}{l}\text { Rhyolites + o - Alkal., Dacites and Subord. Trachytes } \\
\text { and Latites }\end{array}$ \\
\hline $\mathrm{AB}$ & dioriti e gabbri & Diorites and Gabri \\
\hline $\mathrm{AC}$ & "Calcare metallifero bergamasco" & Limestones \\
\hline $\mathrm{AD}$ & Sc.di Edolo/Fill.di Ambria/Micasc. di Maniv & Phyllites and Philladic Micascists "Quartz Phyllites" auct. \\
\hline $\mathrm{AE}$ & Calcare di Camorelli & Limestones \\
\hline $\mathrm{AF}$ & Dolomia dell'Albiga & Dolomites \\
\hline AG & Calcare di Perledo-Varenna & Limestones \\
\hline $\mathrm{AH}$ & Depositi terrazzati (Alluvium medio) & Gravels, Sands and Silts \\
\hline AI & pegmatiti (intercal.nei basam.cristallini) & Pegmatites \\
\hline AJ & Fmz. di Bellano & Conglomerates, Sandstones \\
\hline $\mathrm{AK}$ & "Ceppo" e fmz. simili, facies "Villafran & Conglomerates, Sands, Clays \\
\hline $\mathrm{AL}$ & Fluvioglaciale, fluviale e lacustre Riss & Ferrettized Gravels, Sands and Clays \\
\hline $\mathrm{AM}$ & Arenaria di Val Sabbia & Sandstones \\
\hline $\mathrm{AN}$ & Fluvioglaciale e Fluviale Wurm & Gravels, Sands \\
\hline $\mathrm{AO}$ & Depositi terrazzati (Alluvium antico) & Gravels, Sands and Silts \\
\hline $\mathrm{AP}$ & "Corna" & Limestones, Dolomites \\
\hline AQ & "Scaglia lombarda" & $\begin{array}{l}\text { Marl, Limestone Marn. Selcif Limestones. Basal tuff } \\
\text { Sandstones. }\end{array}$ \\
\hline
\end{tabular}

207 The SPI and TWI are two important hydrological parameters that are frequently used in the landslide208 related analysis (Nsengiyumva et al. 2019, Saha and Saha 2021). The SPI denotes the erosive 209 potential of the streams (Kumar and Anbalagan 2016) and TWI is an indicator of soil moisture 210 contents that contribute to the occurrence of landslide (Pokharel et al. 2021). Given $\beta$ as the steepness 211 of terrain and $S C A$ as specific catchment area, Equations 1 and 2 express the formulation of these 212 conditioning factors: 


$$
\begin{aligned}
& S P I=S C A \times \tan \beta \\
& T W I=\ln (S C A / \tan \beta)
\end{aligned}
$$

213 Figures 2 - (1) and (m) exhibit the maps produced for the SPI and TWI, respectively. The values of 214 both layers are classified into five classes. For the SPI the sub-groups are (0.01 - 1488.30), (1488.30 215 - 10418.13), (10418.13 - 32742.70), (32742.70 - 116087.75), and >116087.75. As for the TWI, (-9.62 $216--2.66),(-2.66-1.78),(1.78-3.72),(3.72-6.34)$, and $>6.34$.

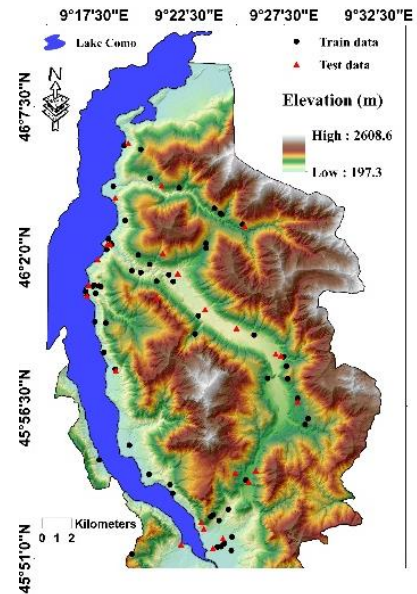

(a)

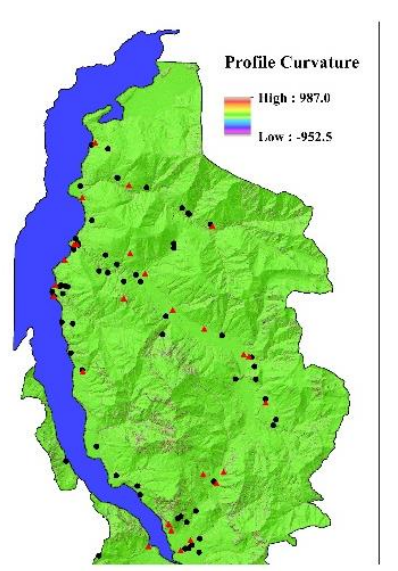

(e)

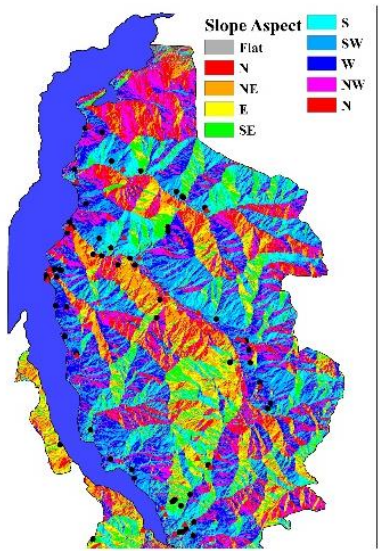

(b)

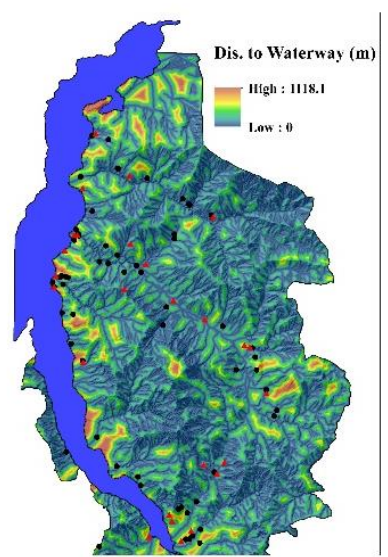

(f)

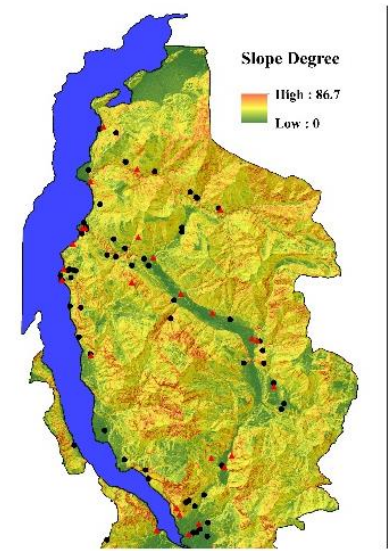

(c)

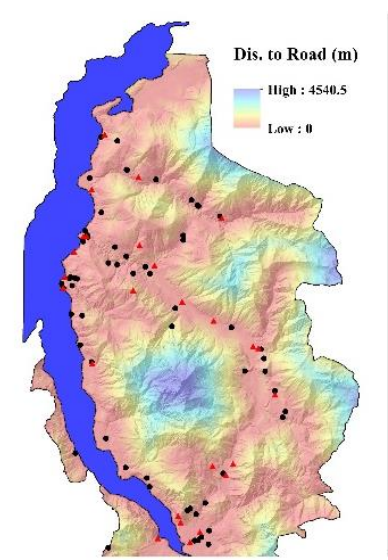

(g)

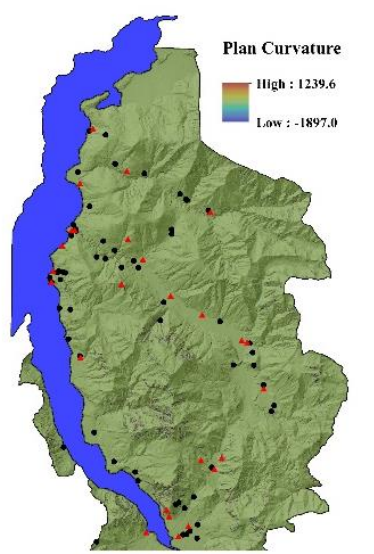

(d)

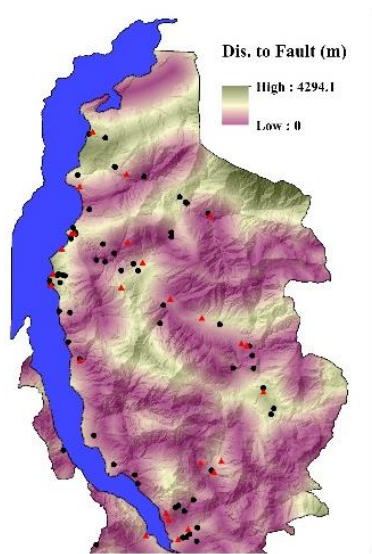

(h) 


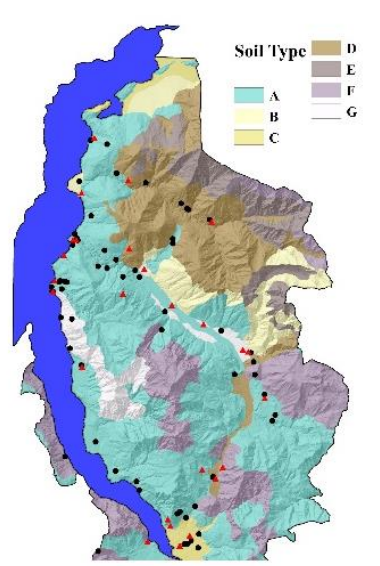

(i)

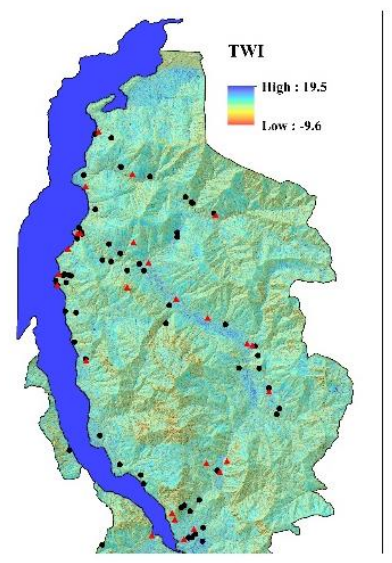

$(\mathrm{m})$

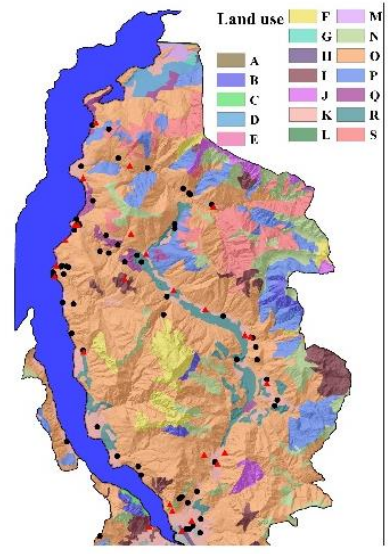

(j)

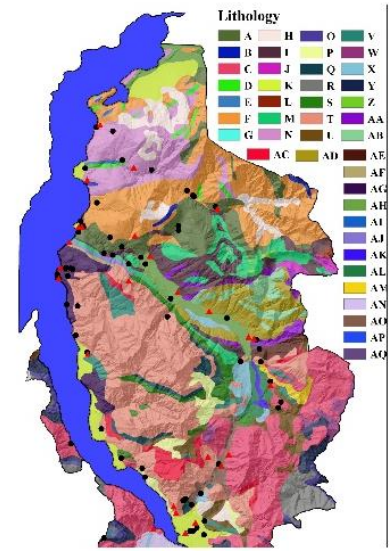

$(\mathrm{k})$

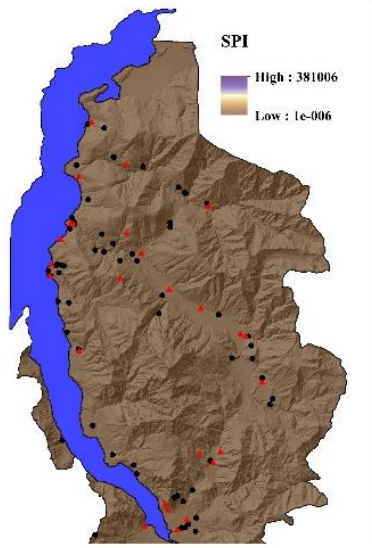

(1)

218 Figure 2: The map of conditioning factor: (a) elevation, (b) slope aspect, (c) slope degree, (d) plan curvature, (e) profile curvature, (f) distance to waterway, (g) distance to road, (h) distance to fault, (i) soil type, (j) land use, (k) lithology, (l) SPI, and (m) TWI

222 For quantifying the relationship between the landslides and conditioning factors, the FR model is employed. Since the FR is one of the models used in this study, it is well explained in the next section.

224 In this method, based on statistical analysis, one value is calculated for each sub-class which 225 determines its correlation with the landslide occurrence. Thus, the larger the FR is, the bigger the contribution of the sub-class is (Huang et al. 2021). Also, the FR values equal to 1 reflect an average 
correlation, while those below 1 and above 1 indicate a lower and higher correlation (Akgün and 228 Bulut 2007).

229 All layers were prepared in the ArcMap with a cell size of $5 \times 5 \mathrm{~m}$. It resulted in layers with 18908558 230 pixels. The FR values were calculated by crossing each layer with the whole landslides. Table 3 gives 231 the results of this process. In the elevation map, the FR values of the first two classes are meaningfully 232 greater than others. In the aspect layer, the FR of South, South-West, and West is larger than 1. 233 Considering the slope map, around $43 \%$ of the landslides are located in slopes $<15^{\circ}$ which cover 234 approximately $14 \%$ of the area. It resulted in an FR value of 2.61. As for the plan curvature and profile 235 curvature layers, the biggest FRs (i.e., 2.44 and 2.64, respectively) are calculated for the fifth and first 236 sub-classes, respectively. Concerning the linear features, while large FRs are obtained for pixels far 237 from the waterway and faults, the pixels close to roads have significantly larger FRs. The biggest FR 238 in this regard is 6.03 for pixels which are at maximum $50 \mathrm{~m}$ off the roads. The sub-classes labeled as 239 C from the soil type layer, L from the land use layer, and AG from the lithology layer are characterized 240 by the largest correlation with the landslides. The smallest SPI sub-class and the largest TWI sub241 class acquired the highest FR which were 1.00 and 1.92, respectively.

Table 3: The details of conditioning factors and FR analysis.

\begin{tabular}{|c|c|c|c|c|c|c|}
\hline Layer & Class & $\begin{array}{c}\text { Number of } \\
\text { Pixels }\end{array}$ & $\begin{array}{l}\text { Percentage } \\
\text { of Pixels }\end{array}$ & $\begin{array}{c}\text { Number of } \\
\text { Landslide Pixels }\end{array}$ & $\begin{array}{l}\text { Percentage of } \\
\text { Landslide } \\
\text { Pixels }\end{array}$ & FR \\
\hline \multirow{6}{*}{$\begin{array}{l}\text { Elevation } \\
\text { (m) }\end{array}$} & $<200$ & 103710 & 0.55 & 656 & 2.41 & 4.39 \\
\hline & $(200-700)$ & 5181809 & 27.40 & 18256 & 67.06 & 2.45 \\
\hline & $(700-1200)$ & 6739888 & 35.64 & 7995 & 29.37 & 0.82 \\
\hline & $(1200-1700)$ & 4830665 & 25.55 & 315 & 1.16 & 0.05 \\
\hline & $(1700-2200)$ & 1894308 & 10.02 & 0 & 0.00 & 0.00 \\
\hline & $>2200$ & 158178 & 0.84 & 0 & 0.00 & 0.00 \\
\hline \multirow{3}{*}{$\begin{array}{l}\text { Slope } \\
\text { Aspect }\end{array}$} & Flat & 53802 & 0.28 & 31 & 0.11 & 0.40 \\
\hline & North & 2276204 & 12.04 & 1647 & 6.05 & 0.50 \\
\hline & North-East & 2025947 & 10.71 & 1785 & 6.56 & 0.61 \\
\hline
\end{tabular}




\begin{tabular}{|c|c|c|c|c|c|c|}
\hline & East & 1618287 & 8.56 & 1344 & 4.94 & 0.58 \\
\hline & South-East & 1807676 & 9.56 & 2243 & 8.24 & 0.86 \\
\hline & South & 2387968 & 12.63 & 4101 & 15.07 & 1.19 \\
\hline & South-West & 3016836 & 15.95 & 7917 & 29.08 & 1.82 \\
\hline & West & 3057814 & 16.17 & 5081 & 18.67 & 1.15 \\
\hline & North-West & 2664024 & 14.09 & 3073 & 11.29 & 0.80 \\
\hline \multirow{5}{*}{$\begin{array}{l}\text { Slope } \\
\text { Degree }\end{array}$} & $<15$ & 3101954 & 16.41 & 11641 & 42.76 & 2.61 \\
\hline & $(15-25)$ & 2997767 & 15.85 & 4841 & 17.78 & 1.12 \\
\hline & $(25-35)$ & 5316245 & 28.12 & 4669 & 17.15 & 0.61 \\
\hline & $(35-45)$ & 4997943 & 26.43 & 2977 & 10.94 & 0.41 \\
\hline & $>45$ & 2494649 & 13.19 & 3094 & 11.37 & 0.86 \\
\hline \multirow{5}{*}{$\begin{array}{c}\text { Plan } \\
\text { Curvature }\end{array}$} & $(-1897.01--59.10)$ & 40029 & 0.21 & 101 & 0.37 & 1.75 \\
\hline & $(-59.10--22.34)$ & 228573 & 1.21 & 543 & 1.99 & 1.65 \\
\hline & $(-22.34--10.09)$ & 557391 & 2.95 & 1067 & 3.92 & 1.33 \\
\hline & $(-10.09-51.16)$ & 18033856 & 95.37 & 25340 & 93.09 & 0.98 \\
\hline & $(51.16-1239.68)$ & 48709 & 0.26 & 171 & 0.63 & 2.44 \\
\hline \multirow{5}{*}{$\begin{array}{c}\text { Profile } \\
\text { Curvature }\end{array}$} & $(-952.57--35.78)$ & 42953 & 0.23 & 163 & 0.60 & 2.64 \\
\hline & $(-35.78--13.05)$ & 249283 & 1.32 & 703 & 2.58 & 1.96 \\
\hline & $(-13.05--5.47)$ & 700050 & 3.70 & 1450 & 5.33 & 1.44 \\
\hline & $(-5.47-39.98)$ & 17879413 & 94.56 & 24805 & 91.12 & 0.96 \\
\hline & $(39.98-987.08)$ & 36859 & 0.19 & 101 & 0.37 & 1.90 \\
\hline \multirow{4}{*}{$\begin{array}{l}\text { Distance to } \\
\text { Waterway } \\
\text { (m) }\end{array}$} & $(0-50)$ & 6322640 & 33.44 & 7138 & 26.22 & 0.78 \\
\hline & $(50-100)$ & 4226169 & 22.35 & 5568 & 20.45 & 0.92 \\
\hline & $(100-150)$ & 2793515 & 14.77 & 3154 & 11.59 & 0.78 \\
\hline & $>150$ & 5566234 & 29.44 & 11362 & 41.74 & 1.42 \\
\hline \multirow{4}{*}{$\begin{array}{c}\text { Distance to } \\
\text { Road (m) }\end{array}$} & $(0-50)$ & 1799980 & 9.52 & 15634 & 57.43 & 6.03 \\
\hline & $(50-100)$ & 1290017 & 6.82 & 3831 & 14.07 & 2.06 \\
\hline & $(100-150)$ & 1033256 & 5.46 & 2458 & 9.03 & 1.65 \\
\hline & $>150$ & 14785305 & 78.19 & 5299 & 19.47 & 0.25 \\
\hline \multirow{5}{*}{$\begin{array}{l}\text { Distance to } \\
\text { Fault (m) }\end{array}$} & $(0-200)$ & 2847357 & 15.06 & 3436 & 12.62 & 0.84 \\
\hline & $(200-400)$ & 2620393 & 13.86 & 2851 & 10.47 & 0.76 \\
\hline & $(400-700)$ & 3341392 & 17.67 & 2758 & 10.13 & 0.57 \\
\hline & $(700-1000)$ & 2599794 & 13.75 & 5723 & 21.02 & 1.53 \\
\hline & $>1000$ & 7499622 & 39.66 & 12454 & 45.75 & 1.15 \\
\hline \multirow{7}{*}{ Soil Type } & A & 8518775 & 45.05 & 14940 & 54.88 & 1.22 \\
\hline & B & 1233376 & 6.52 & 776 & 2.85 & 0.44 \\
\hline & $\mathrm{C}$ & 509657 & 2.70 & 2308 & 8.48 & 3.15 \\
\hline & D & 3024208 & 15.99 & 3918 & 14.39 & 0.90 \\
\hline & $\mathrm{E}$ & 1386236 & 7.33 & 0 & 0.00 & 0.00 \\
\hline & $\mathrm{F}$ & 3414946 & 18.06 & 2052 & 7.54 & 0.42 \\
\hline & G & 821360 & 4.34 & 3228 & 11.86 & 2.73 \\
\hline \multirow{7}{*}{ Land Use } & A & 1186813 & 6.28 & 37 & 0.14 & 0.02 \\
\hline & B & 706696 & 3.74 & 1884 & 6.92 & 1.85 \\
\hline & $\mathrm{C}$ & 252132 & 1.33 & 1189 & 4.37 & 3.28 \\
\hline & D & 1726408 & 9.13 & 275 & 1.01 & 0.11 \\
\hline & $\mathrm{E}$ & 9863373 & 52.16 & 9314 & 34.21 & 0.66 \\
\hline & F & 1591860 & 8.42 & 630 & 2.31 & 0.27 \\
\hline & G & 78409 & 0.41 & 212 & 0.78 & 1.88 \\
\hline
\end{tabular}




\begin{tabular}{|c|c|c|c|c|c|c|}
\hline & $\mathrm{H}$ & 7747 & 0.04 & 0 & 0.00 & 0.00 \\
\hline & I & 1033214 & 5.46 & 12210 & 44.85 & 8.21 \\
\hline & $\mathrm{J}$ & 279027 & 1.48 & 0 & 0.00 & 0.00 \\
\hline & $\mathrm{K}$ & 762117 & 4.03 & 315 & 1.16 & 0.29 \\
\hline & $\mathrm{L}$ & 22735 & 0.12 & 315 & 1.16 & 9.62 \\
\hline & $\mathrm{M}$ & 66065 & 0.35 & 0 & 0.00 & 0.00 \\
\hline & $\mathrm{N}$ & 699371 & 3.70 & 0 & 0.00 & 0.00 \\
\hline & $\mathrm{O}$ & 63175 & 0.33 & 810 & 2.98 & 8.91 \\
\hline & $\mathrm{P}$ & 200116 & 1.06 & 0 & 0.00 & 0.00 \\
\hline & Q & 43961 & 0.23 & 0 & 0.00 & 0.00 \\
\hline & $\mathrm{R}$ & 242654 & 1.28 & 0 & 0.00 & 0.00 \\
\hline & $\mathrm{S}$ & 82685 & 0.44 & 31 & 0.11 & 0.26 \\
\hline \multirow{36}{*}{ Lithology } & A & 925626 & 4.90 & 2249 & 8.26 & 1.69 \\
\hline & B & 53518 & 0.28 & 0 & 0.00 & 0.00 \\
\hline & $\mathrm{C}$ & 2485449 & 13.14 & 1796 & 6.60 & 0.50 \\
\hline & $\mathrm{D}$ & 113803 & 0.60 & 102 & 0.37 & 0.62 \\
\hline & $\mathrm{E}$ & 28220 & 0.15 & 0 & 0.00 & 0.00 \\
\hline & $\mathrm{F}$ & 2146026 & 11.35 & 3182 & 11.69 & 1.03 \\
\hline & $\mathrm{G}$ & 1525 & 0.01 & 0 & 0.00 & 0.00 \\
\hline & $\mathrm{H}$ & 614398 & 3.25 & 0 & 0.00 & 0.00 \\
\hline & I & 706462 & 3.74 & 1640 & 6.02 & 1.61 \\
\hline & $\mathrm{J}$ & 80519 & 0.43 & 0 & 0.00 & 0.00 \\
\hline & K & 717208 & 3.79 & 3429 & 12.60 & 3.32 \\
\hline & $\mathrm{L}$ & 22197 & 0.12 & 0 & 0.00 & 0.00 \\
\hline & M & 573513 & 3.03 & 36 & 0.13 & 0.04 \\
\hline & $\mathrm{N}$ & 1142350 & 6.04 & 1874 & 6.88 & 1.14 \\
\hline & $\mathrm{O}$ & 160430 & 0.85 & 0 & 0.00 & 0.00 \\
\hline & $\mathrm{P}$ & 281857 & 1.49 & 595 & 2.19 & 1.47 \\
\hline & Q & 214178 & 1.13 & 167 & 0.61 & 0.54 \\
\hline & $\mathrm{R}$ & 388988 & 2.06 & 211 & 0.78 & 0.38 \\
\hline & $S$ & 341157 & 1.80 & 0 & 0.00 & 0.00 \\
\hline & $\mathrm{T}$ & 3287997 & 17.39 & 3480 & 12.78 & 0.74 \\
\hline & $\mathrm{U}$ & 420514 & 2.22 & 537 & 1.97 & 0.89 \\
\hline & $\mathrm{V}$ & 283656 & 1.50 & 316 & 1.16 & 0.77 \\
\hline & $\mathrm{W}$ & 185634 & 0.98 & 0 & 0.00 & 0.00 \\
\hline & $X$ & 257244 & 1.36 & 95 & 0.35 & 0.26 \\
\hline & $\mathrm{Y}$ & 386464 & 2.04 & 99 & 0.36 & 0.18 \\
\hline & $\mathrm{Z}$ & 20293 & 0.11 & 0 & 0.00 & 0.00 \\
\hline & AA & 215974 & 1.14 & 294 & 1.08 & 0.95 \\
\hline & $\mathrm{AB}$ & 298637 & 1.58 & 0 & 0.00 & 0.00 \\
\hline & $\mathrm{AC}$ & 310488 & 1.64 & 0 & 0.00 & 0.00 \\
\hline & $\mathrm{AD}$ & 609699 & 3.22 & 875 & 3.21 & 1.00 \\
\hline & $\mathrm{AE}$ & 115341 & 0.61 & 0 & 0.00 & 0.00 \\
\hline & $\mathrm{AF}$ & 26950 & 0.14 & 9 & 0.03 & 0.23 \\
\hline & $\mathrm{AG}$ & 362033 & 1.91 & 2846 & 10.45 & 5.46 \\
\hline & $\mathrm{AH}$ & 471572 & 2.49 & 1554 & 5.71 & 2.29 \\
\hline & AI & 10603 & 0.06 & 0 & 0.00 & 0.00 \\
\hline & AJ & 47214 & 0.25 & 215 & 0.79 & 3.16 \\
\hline
\end{tabular}




\begin{tabular}{ccccccc}
\hline & AK & 42261 & 0.22 & 0 & 0.00 & 0.00 \\
& AL & 135095 & 0.71 & 170 & 0.62 & 0.87 \\
AM & 84775 & 0.45 & 0 & 0.00 & 0.00 \\
AN & 136238 & 0.72 & 217 & 0.80 & 1.11 \\
& AO & 198793 & 1.05 & 1234 & 4.53 & 4.31 \\
& AP & 2545 & 0.01 & 0 & 0.00 & 0.00 \\
& AQ & 1114 & 0.01 & 0 & 0.00 & 0.00 \\
\hline \multirow{3}{*}{ SPI } & $(0.01-1488.30)$ & 18785148 & 99.35 & 27122 & 99.63 & 1.00 \\
& $(1488.30-10418.13)$ & 110058 & 0.58 & 97 & 0.36 & 0.61 \\
& $(32742.70-116087.75)$ & 1036 & 0.01 & 3 & 0.01 & 0.17 \\
& $>116087.75$ & 21 & 0.00 & 0 & 0.00 & 0.00 \\
& $(-9.62--2.66)$ & 1901680 & 10.06 & 4241 & 0.00 & 0.00 \\
\hline \multirow{3}{*}{ TWI } & $(-2.66-1.78)$ & 4226507 & 22.35 & 5461 & 20.06 & 0.90 \\
& $(1.78-3.72)$ & 7672662 & 40.58 & 7870 & 28.91 & 0.71 \\
& $(3.72-6.34)$ & 4158012 & 21.99 & 7031 & 25.83 & 1.17 \\
& $>6.34$ & 949697 & 5.02 & 2619 & 9.62 & 1.92 \\
\hline
\end{tabular}

\section{Methodology}

246 The strategy taken for fulfilling this objective is depicted in Figure 3. After proper provision of

247 landslide conditioning factors and inventory map, the FR model delineates the spatial correlation 248 between the landlised and conditioning factors. The database is then divided into the training and 249 testing subsets. Utilizing the training set, the FR, MLPNN, and ANFIS models are executed to 250 calculate landslide susceptibility values (LSVs) over the study area in order to produce the 251 susceptibility maps. The accuracy of the produced maps is evaluated with the help of testing points. 252 Following this, a comparison points out the most accurate evaluative model. Finally, an explicit 253 formula is derived from the MLPNN model to be used for conveniently approximating the LSV. 


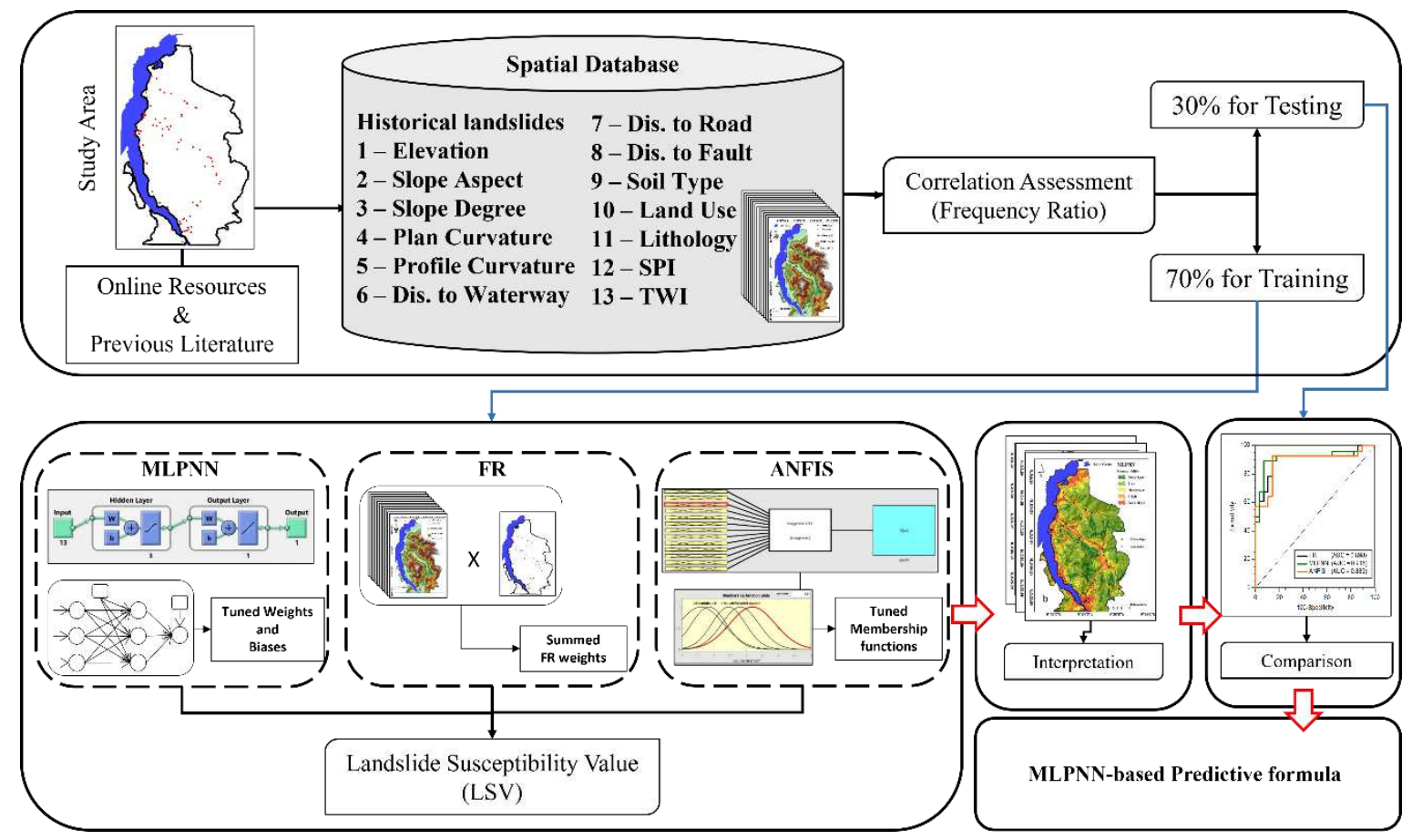

Figure 3: The graphical methodology of this research.

258 The mechanism of the employed models (i.e., FR, MLPNN, and ANFIS) is explained in the 259 following.

\subsection{Frequency Ratio}

262 The FR model is a simple bivariate statistical approach that enables the user to acquire a quantitative

263 representation from the spatial relationship between the landslide and conditioning factors (Termeh

264 et al. 2018). It is a broadly used tool for probabilistic assessments of natural hazards in which multi-

265 classified maps are involved (Bonham-Carter 1994).

266 In the FR method, each sub-class is distinguished by a weight, for calculating which, two questions

267 should be regarded. Assuming the landslide susceptibility problem, the questions are: (a) what 
percentage of landslide pixels are included in this sub-class? and (b) what percentage of the whole

269 area does this sub-class cover? Equation 3 can be written as follows:

$$
F R=\frac{l / L}{a / A}
$$

270 in which $l$ represent the number of landslide pixels included in the sub-class of interest, $L$ is the

271 number of all landslide pixels, $a$ symbolizes the number of pixels corresponding to the sub-class of 272 interest, and $A$ is the number of pixels all over the study area. The LSV of each pixel is finally 273 calculated by summing the FR values obtained for all conditioning factors.

\subsection{MLPNN}

An MLPNN is a specific powerful type of ANNs that is distinguished by its layered structure (Hornik 1991). Generally speaking, ANNs are deemed as simulated biological neural networks which are capable of exploring complex engineering problems (Hornik et al. 1989, Seyedashraf et al. 2018). Provided a numerical dataset, the network uses part of the data for pattern recognition (i.e., training) and the rest is exposed to the obtained knowledge as testing data. Since the model has not met with

281 the testing data before, the testing performance can represent the generalization power of the model. 282 The components of an MLPNN are neurons (A.K.A nodes) that are connected by synapses. As Figure 2834 depicts the MLPNN used in this study, the connection is handled by weights (black arrows). These 284 weights, as well as some bias terms (blue arrows), are tunable through the training process. 


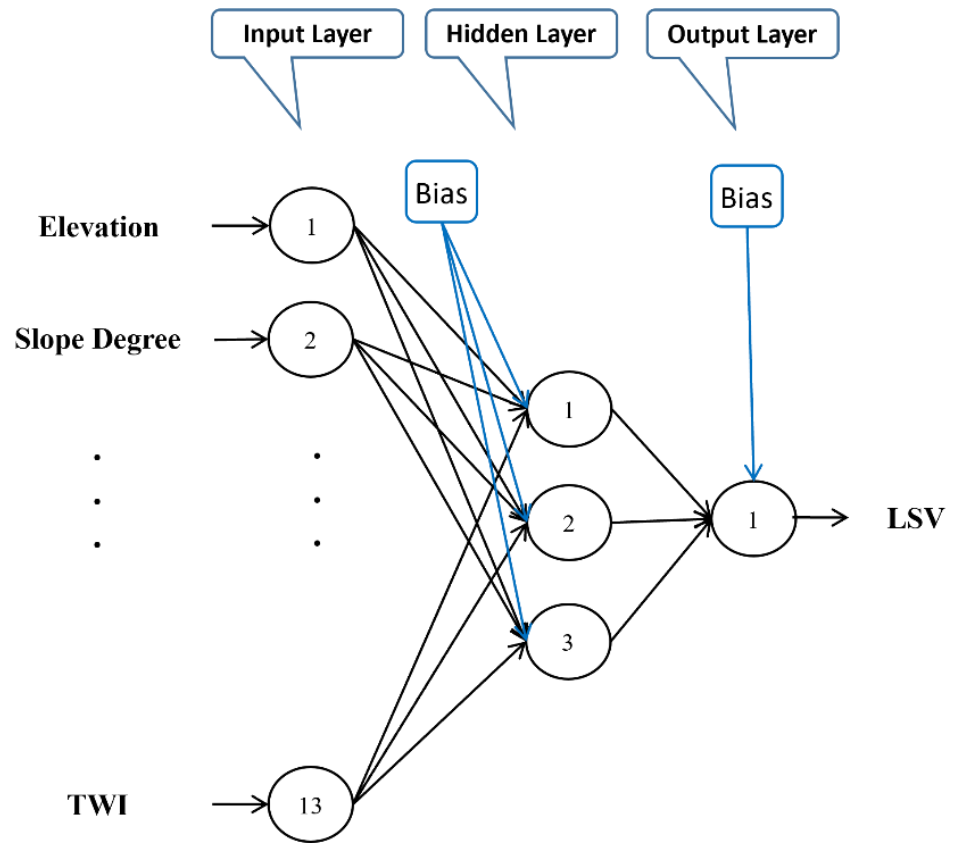

Figure 4: The structure of the used MLPNN.

289 Utilizing specific training strategies (e.g., backpropagation technique associated with the Levenberg290 Marquardt algorithm (Moré 1978)) the neurons perform calculations in the form of Equation 4 to 291 establish a non-linear dependency between the LSV and conditioning factors.

$$
\text { Output }=g(W \times C F+b)
$$

292 where $W$ and $b$ signify the involved weight and bias, respectively. Also, $C F$ is the conditioning factor 293 and $g()$ represents the activation function of the neuron.

\subsection{ANFIS}

296 An ANFIS is a hybrid tool composed of the intelligent computational strategy of the ANN and fuzzy 297 logic. This model was designed by Jang (1993). Taking the advantage of if-then rules with respect to 298 human experience, fuzzy logic attempts to map non-linear complexities into scalar formats. The 
299 calculations in a fuzzy-based model draw on three major processors, namely fuzzification, a fuzzy 300 inference engine, and defuzzification. Based on this idea, crisp values are transformed into a linguistic 301 fuzzy variable for feeding a FIS. The FIS then uses implication operations to apply so-called elements 302 "fuzzy rules" to fuzzy variables. Lastly, the outcome of this process is converted into crisp format 303 again (i.e., defuzzification procedure) (Alajmi and Almeshal 2020). Equivalent to the weights and 304 biases in an ANN, the parameters of the fuzzy membership functions are tunable items in the ANFIS.

\subsection{Accuracy indicators}

307 Plotting the receiving operating characteristic (ROC) curve, along with computing the area beneath 308 it, i.e., the AUC index, is a recognized accuracy evaluation approach in such studies (Zabihi et al. 309 2018, Moayedi et al. 2019, Nguyen et al. 2019, Jiang et al. 2021). The ROC diagram draws specificity 310 on the $x$-axis versus sensitivity on the $y$-axis. Sensitivity denotes the proportion of correctly classified

311 landslide pixels, while specificity is expressed as the proportion of correctly classified non-landslide 312 pixels. Having TP, TN, FP, and FN as true positive, true negative, false positive, and false negative, 313 respectively, specificity and sensitivity are calculated as follows (Chen et al. 2017, $\underline{\text { Hong, Liu et al. }}$ 314 2018):

Sensitivity $=\frac{T P}{T P+F N}$

Specificity $=\frac{T N}{F P+T N}$

315 Note that the TP and TN stand for the numbers of correctly classified pixels, whereas FP and FN signify the numbers of erroneously classified pixels. 
317 Moreover, two error indicators, namely mean square error (MSE) and mean absolute error (MAE)

318 are used to calculate the error of prediction. Let $L S V_{i_{\text {expected }}}$ and $L S V_{i_{\text {modelled }}}$ represent the real (i.e.,

3190 and 1) and predicted LSVs, respectively, the MSE and MAE are defined as follows:

$$
\begin{aligned}
& M S E=\frac{1}{Z} \sum_{i=1}^{Z}\left(L S V_{i_{\text {expected }}}-L S V_{i_{\text {modelled }}}\right)^{2} \\
& M A E=\frac{1}{Z} \sum_{i=1}^{Z}\left|L S V_{i_{\text {expected }}}-L S V_{i_{\text {modelled }}}\right|
\end{aligned}
$$

320 in which the number of landslide points is represented by $Z$ (which equals 128 for the training dataset 321 and 56 for the testing dataset).

\section{Results}

324 To fulfill the purpose of the study, statistical and intelligent models are used to analyze the 325 relationship between the landslide and its conditioning factors, and subsequently, predict the 326 susceptibility for the area of interest. The results of the research are presented in this section. First, 327 an importance analysis is carried out to evaluate the contribution of each conditioning factor. Next, 328 the implementation of the models is explained, and after producing the landslide susceptibility maps, 329 the accuracy of the models is assessed and compared.

\subsection{Importance analysis}

332 The importance of each landslide conditioning factor is investigated using an unbiased predictor

333 importance approach. In this regard, a random forest (RF), i.e., a bagged ensemble, composed of 200 334 regression trees is trained in the Matlab environment (Zheng et al. 2020, Moayedi et al. 2021). Figure 
3355 shows the obtained importance values (IVs) in the form of column charts. It is clearly seen that 336 distance to road (IV $=2.62)$ plays the most important role in this dataset. After that, elevation $(\mathrm{IV}=$ 337 2.62), slope degree (IV $=0.41)$, and slope aspect $(\mathrm{IV}=0.38)$ have the largest contributions.

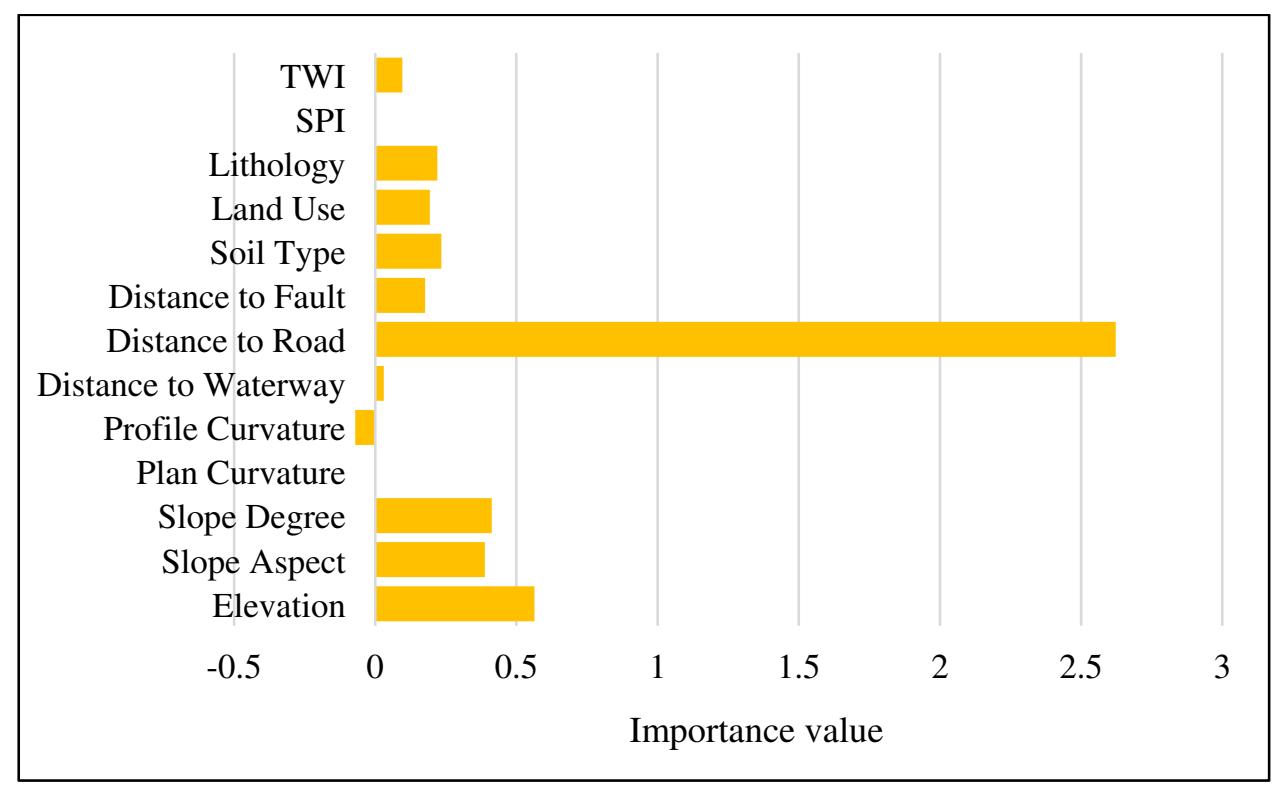

Figure 5: The results of the importance assessment.

\subsection{Model implementation}

343 For all three models, the training data are used for acquiring the knowledge regarding the landslide 344 pattern and the susceptibility maps are produced accordingly. More clearly, based on the existing 345 events, the model conducts specific calculations to explore the landslide pattern and applies this 346 knowledge to the whole area for producing the landslide susceptibility map. 


\subsubsection{FR}

349 For producing the landslide susceptibility map using FR, the training events were crossed with the

350 classified map of the conditioning factor to calculate the $l / L_{L}$ and $a / A$ ratios (see Equation 3).. After 351 calculating the FR value for each sub-class, the susceptibility map was obtained as the sum of all 352 weight layers. It is worth noting that the FR values used for producing this map were different from 353 those presented in Table 3 as the values in this table are calculated when all landslides are concerned.

\subsubsection{Artificial intelligence models}

356 Implementing intelligent models like the MLPNN and ANFIS entails providing appropriate numerical data to feed their networks. The values of thirteen conditioning factors were extracted to a total of 184 points (having 92 landslides and 92 non-landslides). Moreover, each point received a target value which was either 0 or 1 if it is a non-landslide or landslide point, respectively. After separating the 56 testing points, a training dataset composed of 128 samples was provided for the MLPNN and ANFIS. They explore this dataset to acquire a non-linear understanding of landslide susceptibility.

\subsubsection{MLPNN}

Due to the number of inputs (i.e., 13) and the unique target parameter, it is immediate that the proposed MLPNN should have 13 input neurons and one output neuron. In contrast, determining the number of hidden neurons is a challenging task in ANN models. Trial and effort, coupled with the user's experience, is a well-tried approach for properly determining this parameter. In this study, 50 MLPNNs with the architecture $13 \times x \times 1(x=1,2,3, \ldots, 50)$ were considered where each one was 
executed 5 times for assessing the repeatability of results. This process revealed that 3 hidden neurons give the best results. Hence, an MLPNNs with the architecture $13 \times 3 \times 1$ was chosen among a total of 250 tested networks. This model was trained by Levenberg-Marquardt (LM) algorithm (Marquardt 1963) which is among the most powerful techniques for this objective. In the training process, based on the influence of conditioning factors on the occurrence of landslides, the weights and biases of the MLPNN were adjusted. Almost in all cases, the divergence of the error (with 6 times tolerance) stopped the training process.

Figure 6 shows the training results. In this figure, the predicted LSVs are compared to the expected ones (i.e., 0 and 1). For each sample, an error value gives the direct difference between these two values, and the frequency of these errors is analyzed in the form of a histogram chart. The calculated values of MSE (0.1115) and MAE (0.2623) associated with this graphical representation indicate acceptable learning carried out by this model.
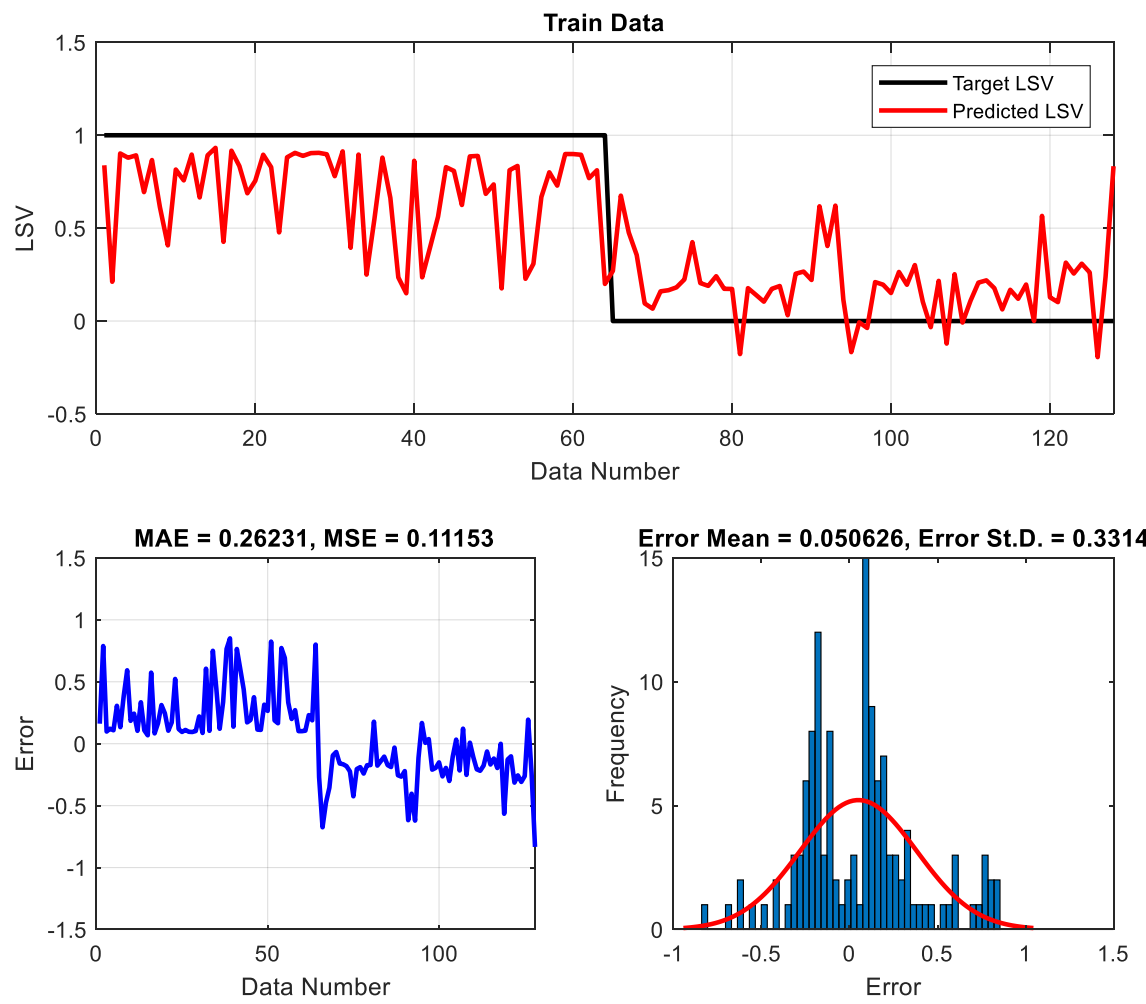
Figure 6: Training results of the MLPNN model.

\subsubsection{ANFIS}

387 Similar to the MLPNN, there are some parameters that should be determined for achieving a reliable 388 implementation of the ANFIS. The number of clusters in a fuzzy inference system can significantly 389 affect the quality of learning. This parameter was tested to be $4,5,6,7$, and 8 (the values outside this 390 range did not yield reasonable training). Each model was repeated 10 times to check the repeatability 391 of results. Finally, out of 50 tested models, the ANFIS with 6 clusters was chosen due to the lowest 392 training error provided by this architecture. Concerning other parameters of the ANFIS, the number 393 of repetitions (i.e., epochs) was set to be 1000. A few greater values were tested as well, but the 394 network experienced negligible changes. Between the Hybrid and Backpropagation optimization 395 methods, the latter method was preferred based on a trial-and-error effort.

396 Figure 7 exhibits the training performance of the ANFIS. As is seen, the network has acquired a good 397 understanding of the behavior of landslides. The responses of the network corresponding to the 398 landslide data tend to 1 , and likewise, those corresponding to the non-landslide data tend to 0. Based 399 on the MAE and MSE values equaling 0.2278 and 0.0932 , respectively, the training error is in an 400 acceptable range. These errors are also smaller than the MLPNN model. 

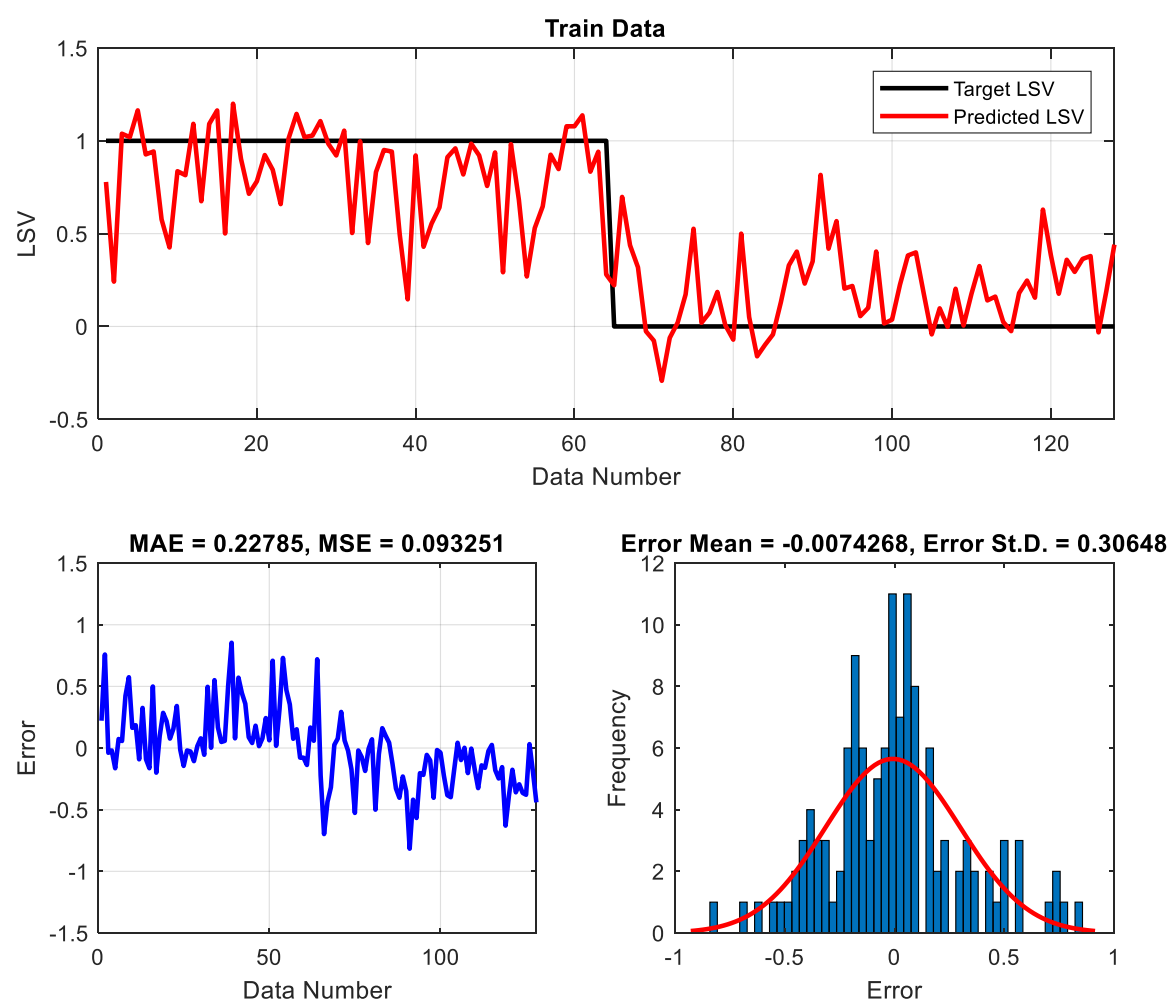

Figure 7: Training results of the ANFIS model.

\subsection{Susceptibility maps and interpretation}

406 Three landslide susceptibility maps are prepared. As explained, the calculations of the FR model were 407 carried out in the ArcGIS and the map was obtained after statistically analyzing spatial interactions. 408 The procedure for producing the susceptibility maps of the MLPNN and ANFIS was different. For 409 all pixels, the values corresponding to thirteen conditioning factors were converted to ASCII format. 410 Then, they were given to the trained networks of MLPNN and ANFIS as new environmental 411 conditions. The models predicted an LSV for each pixel and the results were imported back into 412 ArcGIS to produce the susceptibility maps.

413 The next step was classification of the maps to propose susceptibility levels within the studied area. 414 To this end, the Natural Break classification technique was applied and yielded five categories 
415 characterizing very low, low, moderate, high, and very high susceptibility. It is worth mentioning that 416 the Natural Break (A.K.A Jenks optimization method) is a well-tried classifier for the maps of natural 417 hazards and phenomena (Pourtaghi et al. 2015, Tehrany et al. 2019). For a certain number of classes, 418 it aims to detect breaks that maximize between-class differences and minimizes within-class variance 419 (Ahmed et al. 2021).

420 Figure 8 - (a), (b), and (c) present the resulted maps. It can be seen that these maps are of good 421 reliability, due to compatibility with the occurred landslides. The location of many previous events 422 has been characterized by high or very high susceptibility. An appreciable point deduced from these 423 maps is the high susceptibility of the northern part of the case study (around the road network) where 424 no landslide has been reported. In contrast, some vast central and eastern regions are represented by 425 green colors exhibiting low susceptibility.

426 To have a better perception of the susceptibility areas, Figure $8-(\mathrm{d})$ shows the places showing very 427 high susceptibility jointly by the FR, MLPNN, and ANFIS models. According to this map, as well as 428 the 3D view shown in Figure 8 - (e), a significant part of the coastline of Lake Como (Lecco side) is 429 deemed as crucially susceptible. For instance, a view of the municipality of Bellano is shown in Figure 4308 - (f) using Google Earth photos. As the yellow marks are seen on the map, this area has before 431 experienced several landslides. 

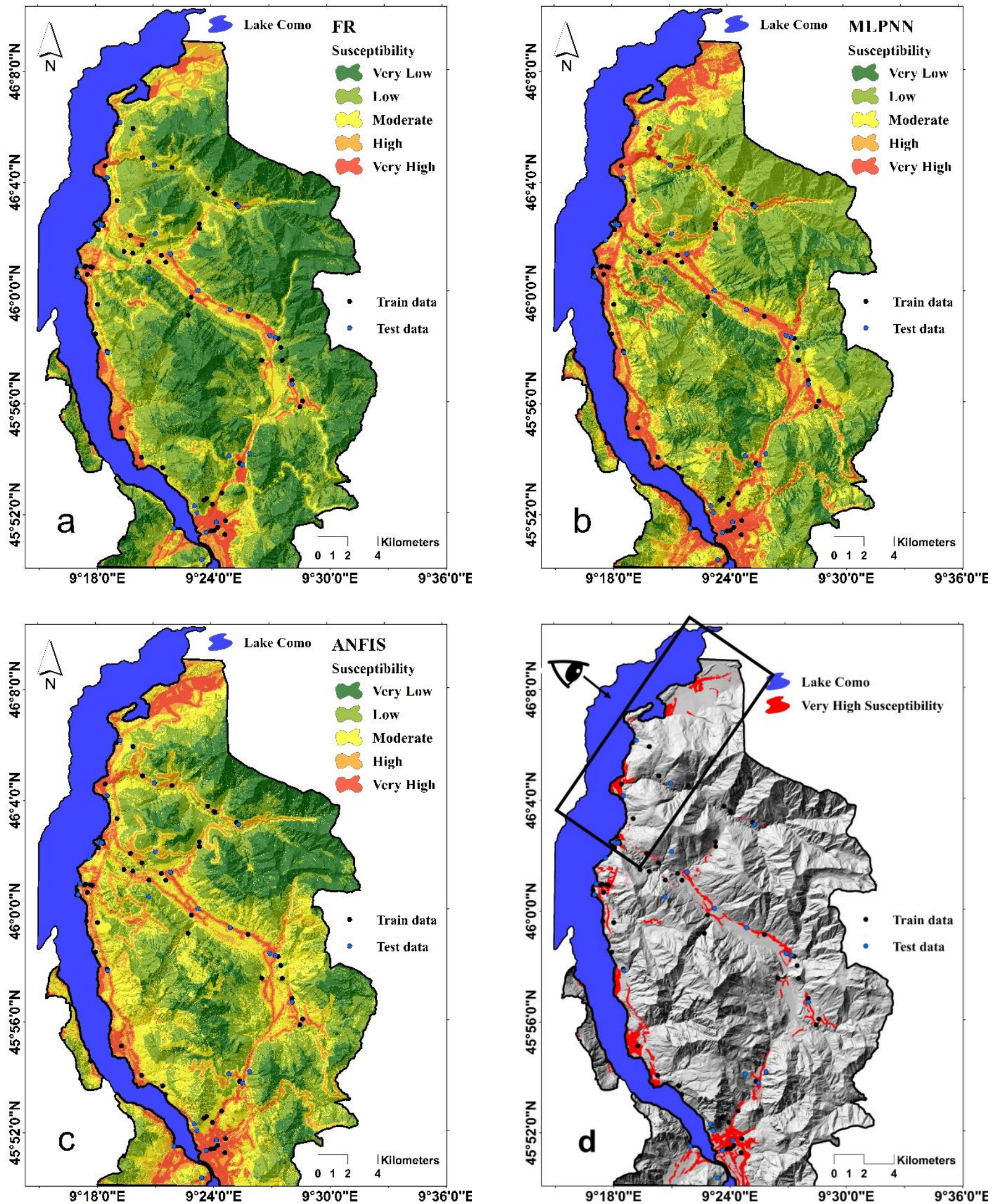


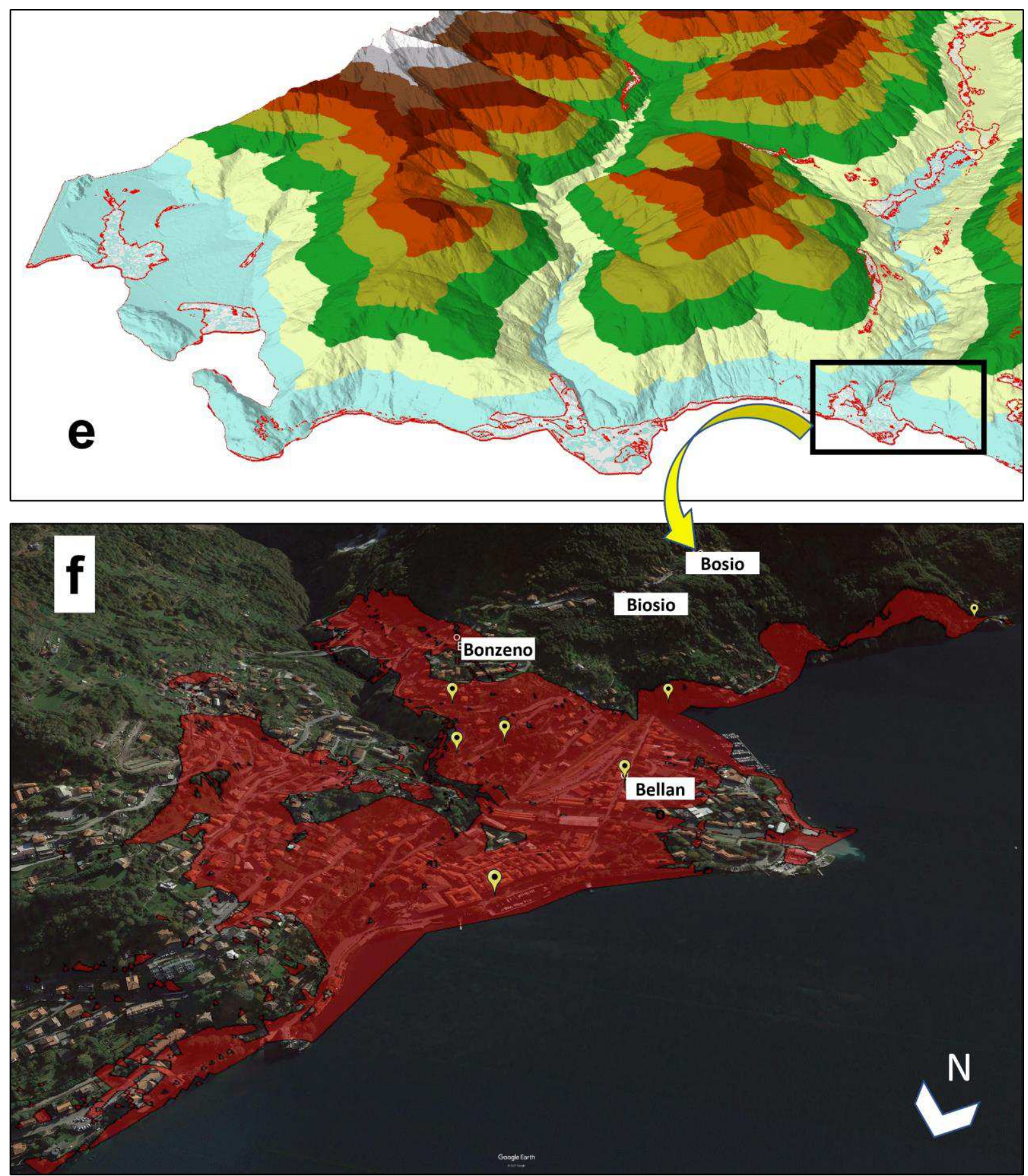

433 Figure 8: The landslide susceptibility maps produced by (a) FR, (b) MLPNN, and (c), ANFIS, (d)

434 very high susceptible areas identified by all three models, (e) a 3D view of Northern parts, and (d) a Google Earth view detailing the susceptibility of the municipality of Bellano. 
Another susceptible line is in the low-height central area. In accordance with the map of conditioning 438 factors, these areas are mostly overlaid with the road networks. The high contribution of the road 439 networks was also inferred from the importance assessment (see Figure 5) where the greatest 440 importance was obtained for the factor distance to road. It necessitates applying proper mitigation 441 measures along the main roads.

442 A notable discrepancy with the expectation is the high susceptibility of gentle terrains. Crossing 443 Figure 8 - (d) with the classified slope map revealed that the slope corresponding to $81.41 \%$ of the 444 susceptible areas is below $15^{\circ}$. This observation can also be supported by the FR analysis (see Table $4453)$ where the biggest FR was observed for this group $\left(<15^{\circ}\right)$ of slope layer. Hence, the areas with 446 gentle slopes may receive equal, and even higher attention, compared to steep areas.

447 The same procedure was repeated for the layers of land use, soil type, and lithology. Areas 448 distinguished with land use code 112 (i.e., discontinuous urban fabric with largest FR $=8.21$ ) have 449 around $77.5 \%$ overlay with Figure $8-(\mathrm{d})$. Likewise, Cambisols and Fluvisols are soil types that 450 contain around half and one-fourth of the crucially susceptible areas, respectively. Concerning the 451 geological units, approximately $40 \%$ of Figure 8 - (d) falls into the K-labeled unit (i.e., Conoids) 452 having an FR value of 3.32 .

453 Table 4 reports the percentage of the area that is covered by each susceptibility class. According to 454 this report, the majority of the area has been categorized as low and very low susceptible. The FR, 455 MLP, and ANFIS have determined 5.03\%, 12.6\%, and 8.12\% of the area as very high susceptible, 456 respectively. Table 4 also demonstrates the percentage of training and testing landslides found in each 457 susceptibility class. Around $45 \%, 66 \%$, and $55 \%$ of the training points, and around $54 \%, 68 \%$, and $45857 \%$ of the testing point are estimated (respectively by the FR, MLPNN, and ANFIS), to be in areas 459 under very high susceptibility. 
461 Table 4: Areal percentage of susceptibility class and intersection with training and testing points.

\begin{tabular}{|c|c|c|c|c|c|c|c|c|c|}
\hline \multirow{2}{*}{$\begin{array}{l}\text { Susceptibility } \\
\text { Class }\end{array}$} & \multicolumn{3}{|c|}{ FR } & \multicolumn{3}{|c|}{ MLPNN } & \multicolumn{3}{|c|}{ ANFIS } \\
\hline & Area & $\begin{array}{l}\text { Training } \\
\text { points }\end{array}$ & $\begin{array}{l}\text { Testing } \\
\text { points }\end{array}$ & Area & $\begin{array}{c}\text { Training } \\
\text { points }\end{array}$ & $\begin{array}{l}\text { Testing } \\
\text { points }\end{array}$ & Area & $\begin{array}{l}\text { Training } \\
\text { points }\end{array}$ & $\begin{array}{l}\text { Testing } \\
\text { points }\end{array}$ \\
\hline Very Low & 38.48 & 1.56 & 7.14 & 13.81 & 1.56 & 0 & 19.68 & 0 & 3.57 \\
\hline Low & 36.22 & 14.06 & 0 & 44.94 & 9.37 & 7.14 & 33.09 & 6.25 & 3.57 \\
\hline Moderate & 12.62 & 7.81 & 25 & 18.28 & 9.37 & 0 & 26.15 & 12.5 & 0 \\
\hline High & 7.62 & 31.25 & 14.28 & 10.35 & 14.06 & 25 & 12.94 & 26.56 & 35.71 \\
\hline Very High & 5.03 & 45.31 & 53.57 & 12.6 & 65.62 & 67.85 & 8.12 & 54.68 & 57.14 \\
\hline
\end{tabular}

\subsection{Validation and comparison}

464 The landslide points that were selected as the testing data were used to examine the accuracy of the 465 maps. It was explained that this study employs the AUC as a common accuracy indicator for all three 466 models. Figure 9 depicts the ROC diagram obtained for the prediction of the FR, MLPNN, and 467 ANFIS. Having a glance at this diagram, all three models have produced susceptibility maps with 468 reliable accuracy. Based on the calculated AUC values, the line corresponding to the MLPNN has 469 the largest area underneath. With 91.6\% accuracy, the MLPNN was the most accurate model, 470 followed by the FR and ANFIS with $89.8 \%$ and $88.9 \%$ accuracy, respectively. 


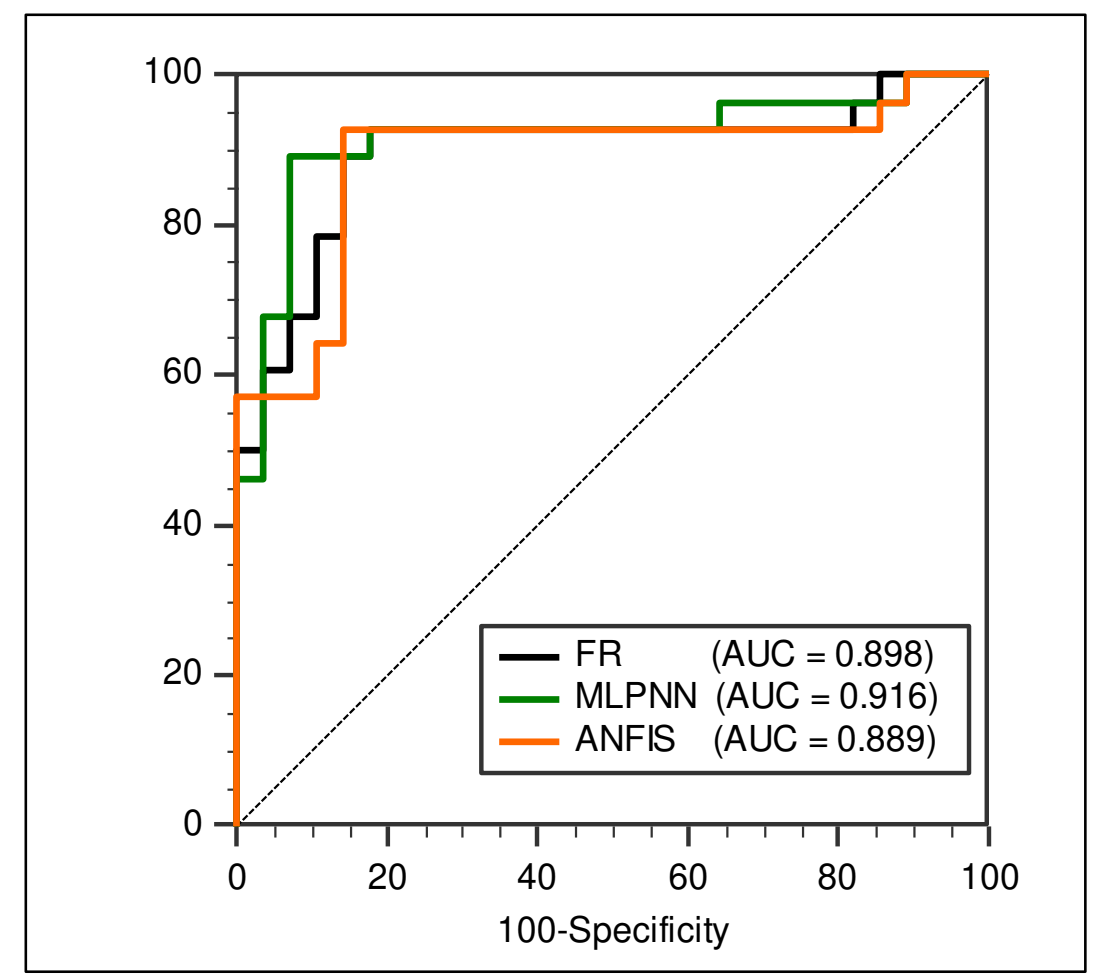

Figure 9: Comparison of the ROC curves.

475 The results of the models are also compared in terms of sensitivity, specificity, and standard error.

476 The sensitivity and specificity of a model indicate true positive and false negative rates in assessing 477 the classification accuracy, which in this case respectively correspond to classifying the landslide and 478 non-landslide points (Bui et al. 2020). With 92.86\% sensitivity, the performance of the FR and ANFIS 479 was superior to MLPNN (sensitivity $=89.29 \%$ ) in the classification of landslides, while the MLPNN, 480 concerning a specificity value of $92.86 \%$, performed the best in the classification of non-landslide 481 points. The calculated specificity values for the FR and ANFIS were $82.14 \%$ and $85.71 \%$, 482 respectively. Furthermore, the lowest standard error was reported for the MLPNN, i.e., 0.0428 vs. $483 \quad 0.0464$ for the FR and 0.0489 for the ANFIS.

484 Referring to the above comparison of the accuracies of classification, the MLPNN could predict the susceptibility of landslide more successfully than the FR and ANFIS. Here, two intelligent models 
486 (i.e., the MLPNN and ANFIS) are also compared in terms of the MSE and MAE which reflect error 487 of prediction. The MSE and MAE of the ANFIS were 0.1425 and 0.2939 , while these values were 4880.1139 and 0.2720 for the MLPNN. Both criteria demonstrate that the neural model was stronger for 489 predicting the landslide pattern in unseen environmental conditions.

\subsection{An explicit LSV formula}

In section 3.2, the prediction strategy of the MLPNN was mathematically described. Therefore, after training the model, its neural configuration exposes an explicit predictive formula that can be used

494 for predicting the LSV. The MLPNN was structured as $13 \times 3 \times 1$ denoting 13 input neurons, 3 hidden neurons, and 1 output neuron. Accordingly, there are $(13 \times 3=) 39$ weights that connect the input and hidden neurons and $(3 \times 1=) 3$ weights that connect the hidden and output neurons (see Figure 4).

497 Also, each of the hidden and output neurons owns a bias term for creating their equations. Altogether, 498 the formula is composed of 46 parameters. Equation 9 expresses the LSV formula wherein distance 499 to waterway, distance to road, and distance to fault are abbreviated as DTW, DTR, and DTF, 500 respectively.

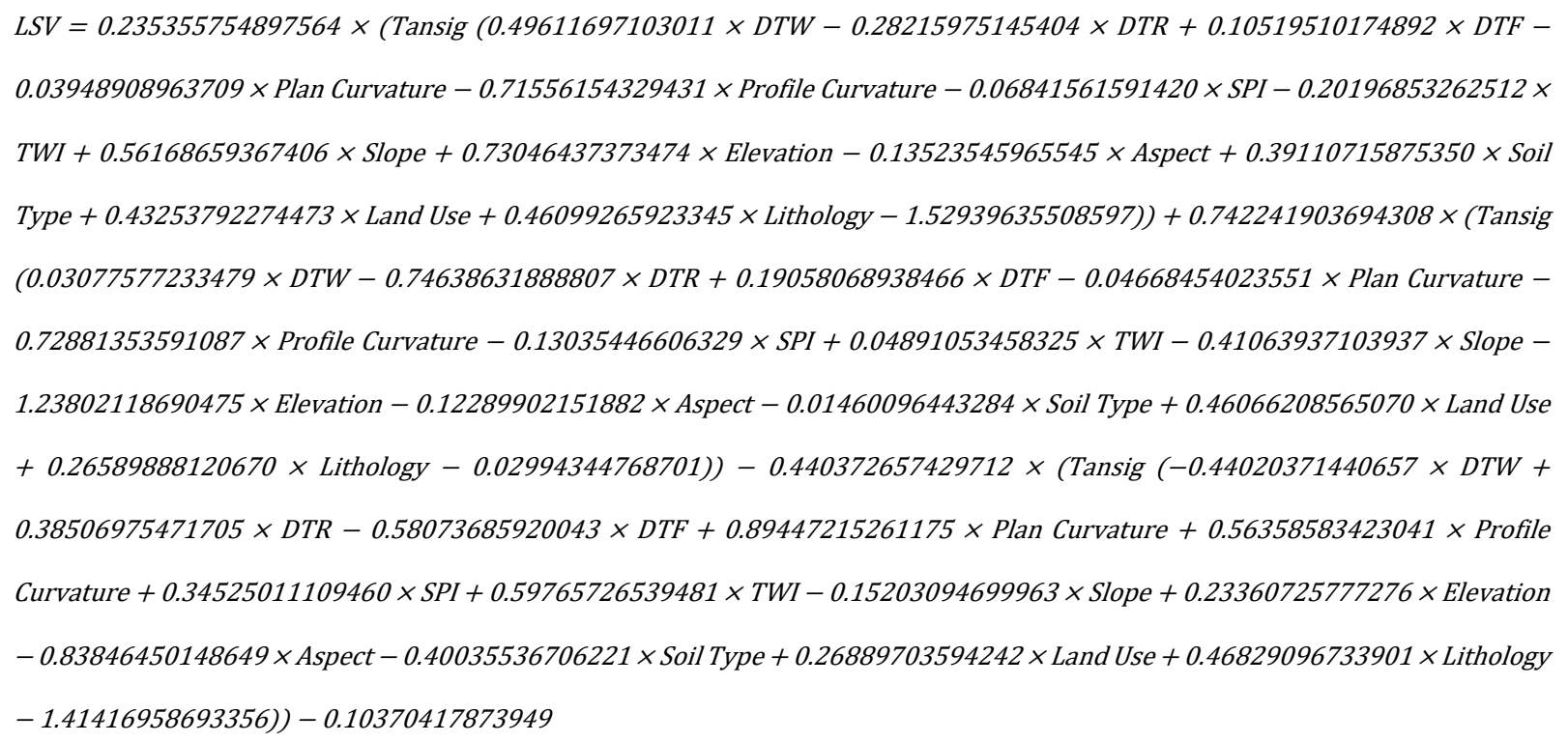


501 where Tansig() is the activation function that is employed by the hidden neurons for producing the

502 local outputs $(g()$ in Equation 4). This function is expressed by Equation 10.

$\operatorname{Tansig}(x)=\frac{2}{1+e^{-2 x}}-1$

\section{Discussion}

\subsection{Problem and solution}

Susceptibility prediction is an effective solution for dealing with environmental threats (Sun et al.

2020, Wei et al. 2021). In the case of landslides, prediction-oriented efforts are of great value to engineers and decision-makers toward providing appropriate mitigation measures and land use planning (go et al. 2021). Up to now, a wide variety of modeling tools and strategies have been proposed to model the susceptibility of landslide all over the world. Concerning the methodologies that require prior landslide events as primary information, statistical-based model and artificial intelligence are among the most popular ones.

513 This study employed the FR and two intelligent models (i.e., MLPNN and ANFIS) for landslide 514 susceptibility prediction in the province of Lecco (Northern half). Using high-resolution data led to 515 producing detailed landslide susceptibility maps. Moreover, accuracy assessments revealed that all 516 three maps can yield a reliable approximation of the susceptible areas. The AUC values corresponding 517 to the prediction phase were $0.898,0.916$, and 0.889 that profess high robustness of all three models 518 against the complexity and non-linearity of the given problem. 


\subsection{A comparative evaluation}

521 From a comparative viewpoint, spatial assessments using bivariate statistical approaches (e.g., FR) 522 are associated with disadvantages like being time-consuming (Yilmaz 2010) and disregarding the 523 interaction between variables (in determining the weight) (Ozdemir 2011). This is while both of these 524 weaknesses are nicely overcome when artificial intelligence techniques are applied. They are capable 525 of automatically tunning the variables in a very efficient way. Nonetheless, a significant difficulty in 526 using intelligent models lies in the necessity of converting the GIS data into pure numerical formats 527 like ASCII. Choosing appropriate hyperparameters is another issue that should be carefully taken care 528 of (Youssef and Pourghasemi 2021). Determining the number of hidden neurons in MLPNN (or the 529 number of clusters in ANFIS) is an example of this challenge that, in the present research, was solved 530 by taking the advantage of the trial-and-error method.

531 Both MLPNN and ANFIS were trained using the backpropagation strategy in which the algorithm 532 propagates backward for rectifying the parameters with respect to the calculated error. The 533 backpropagation is a capable landslide evaluative model which has been successfully tried by scholars 534 like Pradhan and Lee (2010) and Wu et al. (2013). Although the ANFIS achieved a more accurate 535 training (MSEs of 0.0932 vs. 0.1115), the testing performance of the ANN was superior (MSEs of 5360.1139 vs. 0.1425). It can reflect the higher flexibility of the MLPNN when it is applied to unseen 537 environmental conditions. Altogether, the MLPNN was introduced as the most efficient landslide 538 evaluative model, based on which, an explicit LSV predictive formula was extracted.

\subsection{Comparison with literature}

541 Based on the provided inventory maps, landslide is considered a frequent major natural disaster in

542 Italy (Trigila et al. 2010). The produced susceptibility maps were in complete agreement with 
historical landslide events of the Lecco Province. Nonetheless, the outcomes are compared with the results of earlier studies conducted for different scales.

From a regional point of view, Lombardy has experienced many landslides, due to which, many scholars have regarded landslide susceptibility modeling in different parts of this region (e.g., Valtellina valley (Van Den Eeckhaut et al. 2012)). Yordanov and Brovelli (2020) produced the landslide susceptibility map of the Val Tartano District (Southern Sondrio) using the SI, LR, and RF approaches. Val Tartano is in the right-hand side proximity of the area examined in the present work. They also investigated the effect of partitioning ratio for forming the training and testing databases. A 70/30 ratio was suggested as the most suitable proportion which is the one used in the present study. In a risk assessment effort conducted by Lari et al. (2009) over the Lombardy Region, significant parts of Lecco, particularly coastlines on both sides of the Lake Como and some central parts, fell into high, very high, and extremely high hydrogeological risk (i.e., the risk of landslides along with floods and snow avalanches) (see Figure 6 - (a) of the cited paper). These hazardous parts have many places in common with landslide susceptibile areas recognized in this study.

The findings of this research also compromise with similar studies carried out at national/international levels. It was here discussed that noticing the significant contribution of road networks and gentle terrains in the occurrence of landslides, the study area requires appropriate attention for risk mitigation. In the attention level map suggested by Trigila and Iadanza (2008), the northern part of Lombardy (including the present studied area) demands high and very high attention with respect to the risk of landslide and utilization of land (see Figure 18 of the cited paper).

The results of Europe-wide landslide susceptibility assessment fulfilled by Van Den Eeckhaut, Hervás et al. (2012) showed that the vicinity of Alp Mountains is considerably more susceptible than the rest. Magnification on the obtained map (see Figure 6-(d) of the cited paper) illustrates that this vicinity includes the north of Italy, and above all, the province of Lecco. 
567 Furthermore, Europe-wide and national-wide landslide susceptibility mappings carried out by 568 Günther et al. (2008) and Trigila et al. (2013), respectively, are in partial accordance with this study. 569 Günther, Reichenbach et al. (2008) presented a probabilistic susceptibility map in which the 570 probability values between 0.8 and 1.00 are most prevalent in the north of Lombardy (see Figure 2 of 571 the cited paper). Similar evaluations can be inferred from the landslide indices calculated by Trigila, 572 Frattini et al. (2013) (see Figure 7 of the cited paper). Also, various global-scale analyses can validate 573 this inference as well (Hong et al. 2007, Stanley and Kirschbaum 2017).

574 Once again, compared to the case of this study, the maps regarded for the above validation were 575 drawn for much wider extents, i.e., national, continental, and global scales. They mostly provide 576 information for decision-making in such levels (e.g., allocating budgets). Hereupon, they cannot be 577 expected to reflect the same details as the local maps do. For instance, the exact distribution of 578 susceptible/not susceptible properties and habitats needs local-scale investigations.

\subsection{Future efforts}

581 Concerning the results of this study, future projects are recommended to focus on a profound landslide 582 risk analysis through assessing the hazard, exposure, and vulnerability over the study area. Proposing 583 mitigation measures (e.g., early warning systems (Pecoraro et al. 2019)) that may reduce the risk of 584 landslide over the populated areas and valuable assets may be another viable subject.

585 Moreover, several ideas can be regarded to improve prediction efficiency. The betterment can happen 586 in terms of accuracy and problem complexity. Employing optimization techniques for both training 587 of the intelligent models and optimizing the number of conditioning factors would be worth trying. 588 Comparative studies are also of high interest for recognizing more effective intelligent models. 
591 Italy, and more particularly Lecco Province, is a landslide-prone area. In this research, reliable 592 susceptibility maps were produced using state-of-the-art models and high-resolution spatial data. The 593 validation of the results reflected good accuracy for all implemented models. However, the MLPNN 594 emerged as a more generalizable predictive tool. The results illustrated a reasonable susceptibility 595 zonation of landslide. Significant areas were jointly recognized as highly susceptible by all three 596 models. There are valuable assets and populated areas falling into this level of susceptibility. 597 Considering the contribution of conditioning factors, it was discussed that slope degree and distance 598 to road factors are expected to be highly regarded for taking mitigation measures. All in all, the 599 findings of this paper can be interesting for alleviating the risk of landslide through land use planning 600 and decision-making within the studied area.

\section{Declarations}

603 Funding: This research received no funding.

604 Conflicts of interest: The author declares that there is no conflict of financial/non-financial interest. 605

606 Acknowledgment

607 The author would like to acknowledge Territorial Information of Region Lombardy 608 (https://www.geoportale.regione.lombardia.it/en/home) for providing valuable geographic 609 information used as the material in this study. 
612 Ahmed, N., et al. (2021). "Spatio-Temporal Assessment of Groundwater Potential Zone in the Drought-Prone 613 Area of Bangladesh Using GIS-Based Bivariate Models." Natural Resources Research: 1-23. 614 https://doi.org/10.1007/s11053-021-09870-0

615 Akgün, A. and F. Bulut (2007). "GIS-based landslide susceptibility for Arsin-Yomra (Trabzon, North Turkey) 616 region." Environmental geology 51(8): 1377-1387. https://doi.org/10.1007/s00254-006-0435-6

617 Al-Abadi, A. M. (2018). "Mapping flood susceptibility in an arid region of southern Iraq using ensemble 618 machine learning classifiers: a comparative study." Arabian Journal of Geosciences 11(9): 1-19. 619 https://doi.org/10.1007/s12517-018-3584-5

620 Alajmi, M. S. and A. M. Almeshal (2020). "Prediction and optimization of surface roughness in a turning 621 process using the ANFIS-QPSO method." Materials 13(13): 2986. https://doi.org/10.3390/ma13132986

Avand, M. and H. Moradi (2021). "Spatial modeling of flood probability using geo-environmental variables and machine learning models, case study: Tajan watershed, Iran." Advances in Space Research 67(10): 31693186. https://doi.org/10.1016/i.asr.2021.02.011

Avtar, R., et al. (2011). "Landslide susceptibility zonation study using remote sensing and GIS technology in the Ken-Betwa River Link area, India." Bulletin of Engineering Geology and the Environment 70(4): 595-606. https://doi.org/10.1007/s10064-011-0368-5

Ayalew, L. and H. Yamagishi (2005). "The application of GIS-based logistic regression for landslide susceptibility mapping in the Kakuda-Yahiko Mountains, Central Japan." Geomorphology 65(1-2): 15-31. https://doi.org/10.1016/i.geomorph.2004.06.010

Bonham-Carter, G. F. (1994). "Geographic information systems for geoscientists-modeling with GIS." Computer methods in the geoscientists 13: 398.

Bui, D. T., et al. (2019). "Spatial pattern analysis and prediction of forest fire using new machine learning approach of Multivariate Adaptive Regression Splines and Differential Flower Pollination optimization: A case study at Lao Cai province (Viet Nam)." Journal of environmental management 237: 476-487. https://doi.org/10.1016/j.jenvman.2019.01.108

637 Bui, D. T., et al. (2020). "Comparing the prediction performance of a Deep Learning Neural Network model with conventional machine learning models in landslide susceptibility assessment." Catena 188: 104426. https://doi.org/10.1016/j.catena.2019.104426

640 Calvello, M. and G. Pecoraro (2018). "Franeltalia: a catalog of recent Italian landslides." Geoenvironmental 641 Disasters 5(1): 1-16. https://doi.org/10.1186/s40677-018-0105-5

642 Can, A., et al. (2019). "Landslide susceptibility mapping at Ovacık-Karabük (Turkey) using different artificial 643 neural network models: comparison of training algorithms." Bulletin of Engineering Geology and the Environment 78(1): 89-102. https://doi.org/10.1007/s10064-017-1034-3

Catani, F., et al. (2005). "Landslide hazard and risk mapping at catchment scale in the Arno River basin." Landslides 2(4): 329-342. https://doi.org/10.1007/s10346-005-0021-0

Chawla, A., et al. (2019). "Landslide susceptibility zonation mapping: A case study from Darjeeling District, eastern Himalayas, India." Journal of the Indian Society of Remote Sensing 47(3): 497-511. https://doi.org/10.1007/s12524-018-0916-6 
Chen, W., et al. (2017). "A novel hybrid artificial intelligence approach based on the rotation forest ensemble and naïve Bayes tree classifiers for a landslide susceptibility assessment in Langao County, China." Geomatics, Natural Hazards and Risk 8(2): 1955-1977. https://doi.org/10.1080/19475705.2017.1401560

653 Chen, Z., et al. (2020). "The influence of DEM spatial resolution on landslide susceptibility mapping in the 654 Baxie River basin, NW China." Natural Hazards 101(3).

Cruden, D. M. (1991). "A simple definition of a landslide." Bulletin of the International Association of Engineering Geology-Bulletin de l'Association Internationale de Géologie de I'Ingénieur 43(1): 27-29. https://doi.org/10.1007/BF02590167

Dou, J., et al. (2020). "Different sampling strategies for predicting landslide susceptibilities are deemed less consequential with deep learning." Science of the total environment 720: 137320. https://doi.org/10.1016/j.scitotenv.2020.137320

661 El-Magd, S. A. A., et al. (2021). "Spatial modeling and susceptibility zonation of landslides using random forest, naïve bayes and K-nearest neighbor in a complicated terrain." Earth Science Informatics: 1-17. https://doi.org/10.1007/s12145-021-00653-y

Fabbri, A. G. and A. Patera (2021). "Spatial Uncertainty of Target Patterns Generated by Different Prediction 665 Models of Landslide Susceptibility." Applied Sciences 11(8): 3341. https://doi.org/10.3390/app11083341

Gayen, A., et al. (2019). "Gully erosion susceptibility assessment and management of hazard-prone areas in India using different machine learning algorithms." Science of the total environment 668: 124-138. https://doi.org/10.1016/j.scitotenv.2019.02.436

Günther, A., et al. (2008). Approaches for delineating areas susceptible to landslides in the framework of the European Soil Thematic Strategy. Proceedings of the first world landslide forum, Tokyo, Citeseer.

Hong, H., et al. (2018). "Landslide susceptibility mapping using J48 Decision Tree with AdaBoost, Bagging and Rotation Forest ensembles in the Guangchang area (China)." Catena 163: 399-413. https://doi.org/10.1016/i.catena.2018.01.005

Hong, H., et al. (2020). "Introducing a novel multi-layer perceptron network based on stochastic gradient descent optimized by a meta-heuristic algorithm for landslide susceptibility mapping." Science of the total environment 742: 140549. https://doi.org/10.1016/j.scitotenv.2020.140549

Hong, Y., et al. (2007). "Use of satellite remote sensing data in the mapping of global landslide susceptibility." Natural Hazards 43(2): 245-256. https://doi.org/10.1007/s11069-006-9104-z

Hornik, K. (1991). "Approximation capabilities of multilayer feedforward networks." Neural networks 4(2): 251-257. https://doi.org/10.1016/0893-6080(91)90009-T

681 Hornik, K., et al. (1989). "Multilayer feedforward networks are universal approximators." Neural networks 682 2(5): 359-366. https://doi.org/10.1016/0893-6080(89)90020-8

683 Hua, Y., et al. (2021). "Dynamic development of landslide susceptibility based on slope unit and deep neural 684 networks." Landslides 18(1): 281-302. https://doi.org/10.1007/s10346-020-01444-0

Huang, F., et al. (2021). "Uncertainty study of landslide susceptibility prediction considering the different attribute interval numbers of environmental factors and different data-based models." Catena 202: 105250. https://doi.org/10.1016/j.catena.2021.105250 
https://www.geoportale.regione.lombardia.it/en/metadati?p p id=detailSheetMetadata WAR gptmetad 691 ataportlet\&p $\mathrm{p}$ lifecycle $=0 \& \mathrm{p} p$ state $=$ normal\&p $\mathrm{p}$ mode=view\& detailSheetMetadata WAR gptmetad ataportlet uuid=\%7B1D4AAE9F-EB7B-4E3E-AB8A-EE29A2211593\%7D. Access Date: 23/07/2021

Jacinth Jennifer, J. and S. Saravanan (2021). "Artificial neural network and sensitivity analysis in the landslide susceptibility mapping of Idukki district, India." Geocarto International: 1-23. https://doi.org/10.1080/10106049.2021.1923831

Jang, J.-S. (1993). "ANFIS: adaptive-network-based fuzzy inference system." IEEE transactions on systems, man, and cybernetics 23(3): 665-685.

Jiang, C., et al. (2021). "Spatial modeling of gully head erosion on the Loess Plateau using a certainty factor and random forest model." Science of the total environment 783: 147040. https://doi.org/10.1016/j.scitotenv.2021.147040

Kalantar, B., et al. (2018). "Assessment of the effects of training data selection on the landslide susceptibility mapping: a comparison between support vector machine (SVM), logistic regression (LR) and artificial neural networks (ANN)." Geomatics, Natural Hazards and Risk 9(1): 49-69. https://doi.org/10.1080/19475705.2017.1407368

Kjekstad, O. and L. Highland (2009). Economic and social impacts of landslides. Landslides-disaster risk reduction, Springer: 573-587. https://doi.org/10.1007/978-3-540-69970-5 30

Kumar, R. and R. Anbalagan (2016). "Landslide susceptibility mapping using analytical hierarchy process (AHP) in Tehri reservoir rim region, Uttarakhand." Journal of the Geological Society of India 87(3): 271-286. https://doi.org/10.1007/s12594-016-0395-8

711 Earth System Sciences 9(6): 2085-2106. https://doi.org/10.5194/nhess-9-2085-2009

712 Lee, S., et al. (2003). "Landslide susceptibility analysis using GIS and artificial neural network." Earth Surface 713 Processes and Landforms: The Journal of the British Geomorphological Research Group 28(12): 1361-1376. 714 https://doi.org/10.1002/esp.593

715 Li, W., et al. (2021). "Stacking ensemble of deep learning methods for landslide susceptibility mapping in the 716 Three Gorges Reservoir area, China." Stochastic Environmental Research and Risk Assessment: 1-22. 717 https://doi.org/10.1007/s00477-021-02032-x

718 Li, Y. and P. Mo (2019). "A unified landslide classification system for loess slopes: A critical review." Geomorphology 340: 67-83. https://doi.org/10.1016/i.geomorph.2019.04.020

Lucchese, L. V., et al. (2021). "Mamdani fuzzy inference systems and artificial neural networks for landslide susceptibility mapping." Natural Hazards 106(3): 2381-2405. https://doi.org/10.1007/s11069-021-04547-6 susceptibility modelling in Rorachu river basin of Sikkim Himalaya, India." Geoscience Frontiers 12(5): 101203. https://doi.org/10.1016/i.gsf.2021.101203

Mandal, S. P., et al. (2018). "Comparative evaluation of information value and frequency ratio in landslide susceptibility analysis along national highways of Sikkim Himalaya." Spatial Information Research 26(2): 127141. https://doi.org/10.1007/s41324-017-0160-0 (CPEC) route using multi-criteria decision-making method." Modeling Earth Systems and Environment: 1-15. https://doi.org/10.1007/s40808-021-01226-0 
Marquardt, D. W. (1963). "An Algorithm for Least-Squares Estimation of Nonlinear Parameters." Journal of the Society for Industrial and Applied Mathematics 11(2): 431-441. https://doi.org/10.1137/0111030

Mathew, J., et al. (2009). "Landslide susceptibility zonation mapping and its validation in part of Garhwal Lesser Himalaya, India, using binary logistic regression analysis and receiver operating characteristic curve method." Landslides 6(1): 17-26. https://doi.org/10.1007/s10346-008-0138-z

Mehrabi, M., et al. (2020). "Optimizing an adaptive neuro-fuzzy inference system for spatial prediction of landslide susceptibility using four state-of-the-art metaheuristic techniques." Sensors 20(6): 1723. https://doi.org/10.3390/s20061723

https://www.geoportale.regione.lombardia.it/en/metadati?p p id=detailSheetMetadata WAR gptmetad ataportlet\&p $p$ lifecycle $=0 \& p \quad p$ state $=$ normal\&p $p$ mode $=v i e w \&$ detailSheetMetadata WAR gptmetad ataportlet uuid=\%7BFC06681A-2403-481F-B6FE-5F952DD48BAF\%7D. Access Date: 23/07/2021

Mirdda, H. A., et al. (2020). "Analysis of bi-variate statistical and multi-criteria decision-making models in landslide susceptibility mapping in lower Mandakini Valley, India." GeoJournal 85(3): 681-701. https://doi.org/10.1007/s10708-019-09991-3

Moayedi, H., et al. (2021). "Quick integrative optimizers for minimizing the error of neural computing in pan evaporation modeling." Engineering with Computers: 1-17. https://doi.org/10.1007/s00366-020-01277-4

Moayedi, H., et al. (2019). "Novel hybrids of adaptive neuro-fuzzy inference system (ANFIS) with several metaheuristic algorithms for spatial susceptibility assessment of seismic-induced landslide." Geomatics, Natural Hazards and Risk 10(1): 1879-1911. https://doi.org/10.1080/19475705.2019.1650126

Moayedi, H., et al. (2019). "Modification of landslide susceptibility mapping using optimized PSO-ANN technique." Engineering with Computers 35(3): 967-984. https://doi.org/10.1007/s00366-018-0644-0

Mohajane, M., et al. (2021). "Application of remote sensing and machine learning algorithms for forest fire mapping in a Mediterranean area." Ecological Indicators 129: 107869. https://doi.org/10.1016/i.ecolind.2021.107869

Mokarram, M. and A. R. Zarei (2018). "Landslide susceptibility mapping using fuzzy-AHP." Geotechnical and Geological Engineering 36(6): 3931-3943. https://doi.org/10.1007/s10706-018-0583-y

Moré, J. J. (1978). The Levenberg-Marquardt algorithm: implementation and theory. Numerical analysis, Springer: 105-116.

Naghibi, S. A., et al. (2016). "GIS-based groundwater potential mapping using boosted regression tree, classification and regression tree, and random forest machine learning models in Iran." Environmental monitoring and assessment 188(1): 1-27. https://doi.org/10.1007/s10661-015-5049-6

Ngo, P. T. T., et al. (2021). "Evaluation of deep learning algorithms for national scale landslide susceptibility mapping of Iran." Geoscience Frontiers 12(2): 505-519. https://doi.org/10.1016/i.gsf.2020.06.013

Nguyen, H., et al. (2019). "Potential of hybrid evolutionary approaches for assessment of geo-hazard landslide susceptibility mapping." Geomatics, Natural Hazards and Risk 10(1): 1667-1693. https://doi.org/10.1080/19475705.2019.1607782

Nhu, V.-H., et al. (2020). "Shallow landslide susceptibility mapping by random forest base classifier and its ensembles in a semi-arid region of Iran." Forests 11(4): 421. https://doi.org/10.3390/f11040421

Nhu, V.-H., et al. (2020). "Shallow landslide susceptibility mapping: A comparison between logistic model tree, logistic regression, naïve bayes tree, artificial neural network, and support vector machine algorithms." 
International journal of environmental research and public health 17(8): 2749.

Nsengiyumva, J. B., et al. (2019). "Comparing probabilistic and statistical methods in landslide susceptibility modeling in Rwanda/Centre-Eastern Africa." Science of the total environment 659: 1457-1472. https://doi.org/10.1016/j.scitotenv.2018.12.248

Oh, H.-J. and B. Pradhan (2011). "Application of a neuro-fuzzy model to landslide-susceptibility mapping for shallow landslides in a tropical hilly area." Computers \& Geosciences 37(9): 1264-1276. https://doi.org/10.1016/j.cageo.2010.10.012

Ozdemir, A. (2011). "GIS-based groundwater spring potential mapping in the Sultan Mountains (Konya, Turkey) using frequency ratio, weights of evidence and logistic regression methods and their comparison." Journal of Hydrology 411(3-4): 290-308. https://doi.org/10.1016/j.jhydrol.2011.10.010

Ozdemir, A. and T. Altural (2013). "A comparative study of frequency ratio, weights of evidence and logistic regression methods for landslide susceptibility mapping: Sultan Mountains, SW Turkey." Journal of Asian Earth Sciences 64: 180-197. https://doi.org/10.1016/j.jseaes.2012.12.014

Panahi, M., et al. (2020). "Spatial prediction of landslide susceptibility using hybrid support vector regression (SVR) and the adaptive neuro-fuzzy inference system (ANFIS) with various metaheuristic algorithms." Science of the total environment 741: 139937. https://doi.org/10.1016/j.scitotenv.2020.139937

Pandey, V. K., et al. (2021). "Implications of landslide inventory in susceptibility modeling along a Himalayan highway corridor, India." Physical Geography: 1-24. https://doi.org/10.1080/02723646.2021.1872857

Parente, F., et al. (2013). "Outcomes and cost evaluation of the first two rounds of a colorectal cancer screening program based on immunochemical fecal occult blood test in northern Italy." Endoscopy 45(01): 27-34. https://doi.org/10.1055/s-0032-1325800

Park, S., et al. (2013). "Landslide susceptibility mapping using frequency ratio, analytic hierarchy process, logistic regression, and artificial neural network methods at the Inje area, Korea." Environmental earth sciences 68(5): 1443-1464. https://doi.org/10.1007/s12665-012-1842-5

Pecoraro, G., et al. (2019). "Monitoring strategies for local landslide early warning systems." Landslides 16(2): 213-231. https://doi.org/10.1007/s10346-018-1068-z

Pham, B. T., et al. (2018). "Spatial prediction of landslides using a hybrid machine learning approach based on random subspace and classification and regression trees." Geomorphology 303: 256-270. https://doi.org/10.1016/j.geomorph.2017.12.008

Pham, B. T., et al. (2019). "A comparison of Support Vector Machines and Bayesian algorithms for landslide susceptibility modelling." $\quad$ Geocarto International $\quad 34(13): \quad$ 1385-1407. https://doi.org/10.1080/10106049.2018.1489422

Pham, Q. B., et al. (2021). "A comparison among fuzzy multi-criteria decision making, bivariate, multivariate and machine learning models in landslide susceptibility mapping." Geomatics, Natural Hazards and Risk 12(1): 1741-1777. https://doi.org/10.1080/19475705.2021.1944330

Pokharel, B., et al. (2021). "Spatial clustering and modelling for landslide susceptibility mapping in the north of the Kathmandu Valley, Nepal." Landslides 18(4): 1403-1419. https://doi.org/10.1007/s10346-020-01558$\underline{5}$

Pourghasemi, H. R., et al. (2013). "Landslide susceptibility mapping using support vector machine and GIS at the Golestan Province, Iran." Journal of Earth System Science 122(2): 349-369. https://doi.org/10.1007/s12040-013-0282-2 
Pourghasemi, H. R., et al. (2012). "Landslide susceptibility mapping using index of entropy and conditional probability models in GIS: Safarood Basin, Iran." Catena 97: 71-84. https://doi.org/10.1016/i.catena.2012.05.005

816 Pourtaghi, Z. S., et al. (2015). "Forest fire susceptibility mapping in the Minudasht forests, Golestan province, Iran." Environmental earth sciences 73(4): 1515-1533. https://doi.org/10.1007/s12665-014-3502-4

Pradhan, B. and S. Lee (2010). "Regional landslide susceptibility analysis using back-propagation neural network model at Cameron Highland, Malaysia." Landslides 7(1): 13-30. https://doi.org/10.1007/s10346009-0183-2

Pradhan, B., et al. (2010). "A GIS-based back-propagation neural network model and its cross-application and validation for landslide susceptibility analyses." Computers, Environment and Urban Systems 34(3): 216-235. https://doi.org/10.1016/j.compenvurbsys.2009.12.004

Pradhan, S. P. and T. Siddique (2020). "Stability assessment of landslide-prone road cut rock slopes in Himalayan terrain: a finite element method based approach." Journal of Rock Mechanics and Geotechnical Engineering 12(1): 59-73. https://doi.org/10.1016/i.jrmge.2018.12.018

Razavi-Termeh, S. V., et al. (2021). "Mapping of landslide susceptibility using the combination of neuro-fuzzy inference system (ANFIS), ant colony (ANFIS-ACOR), and differential evolution (ANFIS-DE) models." Bulletin of Engineering Geology and the Environment 80(3): 2045-2067. https://doi.org/10.1007/s10064-020-02048$\underline{7}$

Regmi, A. D., et al. (2014). "Application of frequency ratio, statistical index, and weights-of-evidence models and their comparison in landslide susceptibility mapping in Central Nepal Himalaya." Arabian Journal of Geosciences 7(2): 725-742. https://doi.org/10.1007/s12517-012-0807-z

Reichenbach, P., et al. (2018). "A review of statistically-based landslide susceptibility models." Earth-Science Reviews 180: 60-91. https://doi.org/10.1016/j.earscirev.2018.03.001

Sadighi, M., et al. (2020). "Assessing landslide susceptibility using machine learning models: a comparison between ANN, ANFIS, and ANFIS-ICA." Environmental earth sciences 79(24): 1-14. https://doi.org/10.1007/s12665-020-09294-8

Saha, A. and S. Saha (2021). "Application of statistical probabilistic methods in landslide susceptibility assessment in Kurseong and its surrounding area of Darjeeling Himalayan, India: RS-GIS approach." Environment, Development and Sustainability 23: 4453-4483. https://doi.org/10.1007/s10668-020-00783-1

Saha, S., et al. (2021). "Prediction of landslide susceptibility in Rudraprayag, India using novel ensemble of conditional probability and boosted regression tree-based on cross-validation method." Science of the total environment 764: 142928. https://doi.org/10.1016/j.scitotenv.2020.142928

Sahin, E. K. (2020). "Comparative analysis of gradient boosting algorithms for landslide susceptibility mapping." Geocarto International: 1-25. https://doi.org/10.1080/10106049.2020.1831623

Seyedashraf, O., et al. (2018). "Novel approach for dam break flow modeling using computational intelligence." Journal of Hydrology 559: 1028-1038. https://doi.org/10.1016/j.jhydrol.2018.03.001

Singh, K. and V. Kumar (2018). "Hazard assessment of landslide disaster using information value method and analytical hierarchy process in highly tectonic Chamba region in bosom of Himalaya." Journal of Mountain science $\mathbf{1 5}(4)$.

Stanley, T. and D. B. Kirschbaum (2017). "A heuristic approach to global landslide susceptibility mapping." Natural Hazards 87(1): 145-164. https://doi.org/10.1007/s11069-017-2757-y 
854 Sterlacchini, S., et al. (2011). "Spatial agreement of predicted patterns in landslide susceptibility maps." 855 Geomorphology 125(1): 51-61. https://doi.org/10.1016/i.geomorph.2010.09.004

856 Sun, D., et al. (2020). "A random forest model of landslide susceptibility mapping based on hyperparameter 857 optimization using Bayes algorithm." 107201. $858 \quad$ https://doi.org/10.1016/j.geomorph.2020.107201

859 Tangestani, M. H. (2009). "A comparative study of Dempster-Shafer and fuzzy models for landslide 860 susceptibility mapping using a GIS: An experience from Zagros Mountains, SW Iran." Journal of Asian Earth 861 Sciences 35(1): 66-73. https://doi.org/10.1016/j.jseaes.2009.01.002

862 Tehrany, M. S., et al. (2019). "A novel ensemble modeling approach for the spatial prediction of tropical forest 863 fire susceptibility using LogitBoost machine learning classifier and multi-source geospatial data." Theoretical 864 and Applied Climatology 137(1): 637-653. https://doi.org/10.1007/s00704-018-2628-9

865 Termeh, S. V. R., et al. (2018). "Flood susceptibility mapping using novel ensembles of adaptive neuro fuzzy 866 inference system and metaheuristic algorithms." Science of the total environment 615: 438-451. 867 https://doi.org/10.1016/j.scitotenv.2017.09.262

868 Thai Pham, B., et al. (2019). "Landslide susceptibility assessment by novel hybrid machine learning 869 algorithms." Sustainability 11(16): 4386. https://doi.org/10.3390/su11164386

870 Trigila, A., et al. (2013). Landslide susceptibility mapping at national scale: the Italian case study. Landslide 871 science and practice, Springer: 287-295. https://doi.org/10.1007/978-3-642-31325-7 38

872 Trigila, A. and C. Iadanza (2008). Landslides in Italy, Italian National Institute for Environmental Protection 873 and Research (ISPRA).

874 Trigila, A., et al. (2010). "Quality assessment of the Italian Landslide Inventory using GIS processing." 875 Landslides 7(4): 455-470. https://doi.org/10.1007/s10346-010-0213-0

876 Vahidnia, M. H., et al. (2010). "A GIS-based neuro-fuzzy procedure for integrating knowledge and data in 877 landslide susceptibility mapping." Computers \& Geosciences 36(9): 1101-1114. 878 https://doi.org/10.1016/j.cageo.2010.04.004

879 Van Den Eeckhaut, M., et al. (2012). "Statistical modelling of Europe-wide landslide susceptibility using 880 limited landslide inventory data." Landslides 9(3): 357-369. https://doi.org/10.1007/s10346-011-0299-z

881 Varnes, D. J. (1984). Landslide hazard zonation: a review of principles and practice.

882 Wei, A., et al. (2021). "A novel combination approach for karst collapse susceptibility assessment using the 883 analytic hierarchy process, catastrophe, and entropy model." Natural Hazards 105(1): 405-430. 884 https://doi.org/10.1007/s11069-020-04317-w

$885 \mathrm{Wu}, \mathrm{X}$., et al. (2013). "Landslide susceptibility mapping using rough sets and back-propagation neural 886 networks in the Three Gorges, China." Environmental earth sciences 70(3): 1307-1318. 887 https://doi.org/10.1007/s12665-013-2217-2

888 https://en.climate-data.org/europe/italy/lombardy/lecco-1099/. Access Date: 23/07/2021

889 https://www.geoportale.regione.lombardia.it/en/metadati?p p id=detailSheetMetadata WAR gptmetad 890 ataportlet\&p $p$ lifecycle $=0 \& p$ p state=normal\&p $p$ mode=view \& detailSheetMetadata WAR gptmetad 891 ataportlet uuid=\%7B7BDF78CD-C179-472F-96BE-072A0EBB6C76\%7D. Access Date: 23/07/2021

892 https://www.geoportale.regione.lombardia.it/en/home. Access Date: 23/07/2021

893 https://land.copernicus.eu/pan-european/corine-land-cover. Access Date: 23/07/2021 
896 Xiao, T., et al. (2019). "Spatial prediction of landslide susceptibility using GIS-based statistical and machine 897 learning models in Wanzhou County, Three Gorges Reservoir, China." Acta Geochimica 38(5): 654-669.

898 Yalcin, A. (2008). "GIS-based landslide susceptibility mapping using analytical hierarchy process and bivariate 899 statistics in Ardesen (Turkey): comparisons of results and confirmations." Catena 72(1): 1-12. 900 https://doi.org/10.1016/j.catena.2007.01.003

901 Yalcin, A., et al. (2011). "A GIS-based comparative study of frequency ratio, analytical hierarchy process, 902 bivariate statistics and logistics regression methods for landslide susceptibility mapping in Trabzon, NE 903 Turkey." Catena 85(3): 274-287. https://doi.org/10.1016/j.catena.2011.01.014

$904 \mathrm{Yi}, \mathrm{Y}$., et al. (2020). "Landslide susceptibility mapping using multiscale sampling strategy and convolutional 905 neural network: A case study in Jiuzhaigou region." Catena 195: 104851. 906 https://doi.org/10.1016/i.catena.2020.104851

907 Yilmaz, I. (2009). "Landslide susceptibility mapping using frequency ratio, logistic regression, artificial neural 908 networks and their comparison: a case study from Kat landslides (Tokat-Turkey)." Computers \& Geosciences 909 35(6): 1125-1138. https://doi.org/10.1016/j.cageo.2008.08.007

910 Yilmaz, I. (2010). "The effect of the sampling strategies on the landslide susceptibility mapping by conditional 911 probability and artificial neural networks." Environmental earth sciences 60(3): 505-519. 912 https://doi.org/10.1007/s12665-009-0191-5

913 Yordanov, V. and M. A. Brovelli (2020). "Application of various strategies and methodologies for landslide 914 susceptibility maps on a basin scale: the case study of Val Tartano, Italy." Applied Geomatics: 1-23. https://doi.org/10.1007/s12518-020-00344-1

919 Youssef, A. M. and H. R. Pourghasemi (2021). "Landslide susceptibility mapping using machine learning 920 algorithms and comparison of their performance at Abha Basin, Asir Region, Saudi Arabia." Geoscience 921 Frontiers 12(2): 639-655. https://doi.org/10.1016/i.gsf.2020.05.010

922 Zabihi, M., et al. (2018). "Spatial modelling of gully erosion in Mazandaran Province, northern Iran." Catena 923 161: 1-13. https://doi.org/10.1016/i.catena.2017.10.010

924 Zheng, S., et al. (2020). "Early prediction of cooling load in energy-efficient buildings through novel optimizer 925 of shuffled complex evolution." Engineering with Computers: 1-15. https://doi.org/10.1007/s00366-020$926 \quad \underline{01140-6}$ 